\title{
Rutting Analysis of 100 mm Diameter Polypropylene Modified Asphalt Specimens Using Gyratory and Marshall Compactors
}

\author{
Serkan Tapkı*, Mustafa Keskin \\ Civil Engineering Department, Anadolu University, Eskişehir 26555, Turkey
}

Received: March 11, 2012; Revised: June 12, 2012

\begin{abstract}
Compaction technique used in Marshall design does not model the process of actual rolling procedures on site exactly. Carrying out laboratory compaction of dense bituminous mixtures with Superpave gyratory compactors is a more realistic way of simulating actual compaction. In this study, mechanical differences of reference and polypropylene modified asphalt mixtures were compared using Superpave gyratory and Marshall compaction methods by carrying out repeated creep tests utilising universal testing machine. In addition, there is no standard Superpave design procedure for $100 \mathrm{~mm}$ diameter samples till date. The other purpose of this study is to propose new standards for the compaction and testing procedures of these $100 \mathrm{~mm}$ specimens. Indeed, extensive studies have shown that the design gyration number should be 40 for reference and 33 for polypropylene modified specimens under medium traffic conditions for the similar and specific type of aggregate sources, bitumen, aggregate gradation, mix proportioning, modification technique and laboratory conditions. Moreover, it was shown that, the asphalt samples produced by Superpave gyratory compactor were much resistant to destructive rutting effects than the asphalt specimens prepared by Marshall design.
\end{abstract}

Keywords: Marshall design, Superpave gyratory compactor, polypropylene fibers, repeated creep testing, universal testing machine, $100 \mathrm{~mm}$ specimens, design gyration number

\section{Introduction}

The creep test, for many years, has been used to estimate the rutting potential of dense bituminous mixtures. This test is conducted by applying a static or a repeated load to an asphalt specimen and measuring the resulting permanent deformation. Extensive studies using the unconfined creep test (also known as simple creep test or uniaxial creep test) as a basis of predicting permanent deformation in dense bituminous mixtures has been conducted up to date ${ }^{1-7}$.

The loss of pavement serviceability is a common result from rutting. A typical serviceability loss occurs when the formation of ruts forces the pavement to crack, which can lead to rapid deterioration of the pavement due to the accumulation of water on the pavement surface. Under normal service conditions, deformations within the bituminous materials occur more frequently during late spring, summer and early fall because of elevated temperature conditions.

Rutting can significantly reduce both structural and functional performance of a pavement. Sometimes the rutting magnitude may not be alarming for structural performance, but it is important from the safety point of view ${ }^{8}$.

To solve this rutting problem in flexible pavements (and other problems such as fatigue and low temperature cracking), scientists have developed some techniques and

*e-mail: cstapkin@anadolu.edu.tr methodologies called "asphalt (bitumen) modification". The most popular bitumen modification technique is polymer modification. To this end, novel binders with improved rheological characteristics are continuously being developed ${ }^{9-13}$.

Understanding the effects of repeated creep which leads to the prediction of rutting potential of dense bituminous mixtures is very important for the design of asphalt pavements. During a hot summer day, a heavy vehicle with full load, travelling on a climbing lane imposes a considerable distress on the pavement structure. The repetition of heavier axle loads becomes more pronounced with the increased amount of traffic. The loads from the repeated traffic can create pronounced amounts of permanent deformation or rutting. Even on straight road sections, because of the slow speed and heavy loads of the trucks and trailers, similar problems can be encountered. The pavement around traffic lights and bus stops are also known to have similar problems. Therefore, visible defects related to rutting are frequently found on these types of road sections.

It can be found in the previous pioneering studies that the creep test must be performed at relatively low stress levels (cannot usually exceed $206.9 \mathrm{kPa}(30 \mathrm{psi})$ ) and low temperature (cannot usually exceed $40^{\circ} \mathrm{C}\left(104^{\circ} \mathrm{F}\right)$ ), otherwise the sample fails prematurely ${ }^{3,14,15}$. The test conditions consist of a static axial stress, $\sigma$, of $100 \mathrm{kPa}$ being 
applied to a specimen for a period of 1 hour at a temperature of $40^{\circ} \mathrm{C}$. These test conditions were standardized following a seminar in Zurich ${ }^{16}$. This test is inexpensive and easy to conduct but the ability of the test to predict performance is extremely questionable $\mathrm{e}^{17}$. In place asphalt mixtures are sometimes prone to truck tire pressures of more than $828 \mathrm{kPa}$ (120 psi) and temperatures higher than $60{ }^{\circ} \mathrm{C}\left(140{ }^{\circ} \mathrm{F}\right)^{18}$. Therefore, the conditions of static (and of course repeated) creep testing do not closely simulate in-place conditions and specifically speaking, there is not any "rule of the thumb" for the testing standards for repeated creep testing via universal testing machines that is being accepted by all of the research counterparts all around the world.

There are various important but "limited" number of studies in the literature that have been published up to date about the utilisation of $100 \mathrm{~mm}$ diameter specimens cored from $150 \mathrm{~mm}$ diameter gyratory compacted specimens for the preparation of laboratory specimens ${ }^{19-26}$. In all through these studies, the effect of compaction method, that is whether gyratory or Marshall compaction method have been utilised, and the resulting mechanical performance of mixes have been investigated. In this study, a further step of analyses has been carried out and the $100 \mathrm{~mm}$ diameter plus approximately $60 \mathrm{~mm}$ long specimens have been mechanically tested in order to compare their mechanical test results under repeated creep testing with the previously tested Marshall specimens under the same test temperature and loading conditions for repeatability necessities. This is one of the major differences in this study of the previous literature. Another very important difference of this study is the utilisation of $3 \mathrm{~mm}$ multifilament polypropylene fibers for the wet basis modification of bituminous samples which are prepared by gyratory compactors. Up to date, no other researcher has utilised this kind of special modifier in the preparation of gyratory compacted asphalt specimens. Furthermore, the optimal gyration numbers of reference and polypropylene modified specimens have been determined respectively. Finally, in order to be able to monitor the tertiary creep region of asphalt specimens under creep testing, a completely different loading pattern, loading stress level and testing temperature than the previous studies have been adopted. This is the most important distinction from the published literature till date ${ }^{27}$.

The first part of this study reviews the available literature on dense bituminous mixtures by the utilization of polypropylene fibers. Afterwards, short information on creep (basically repeated) testing of dense bituminous mixtures is presented spanning in the last two decades about the actual loading simulation efforts being undertaken in the laboratory environment. Then, the utilisation of Superpave gyratory compactors in the preparation of especially $100 \mathrm{~mm}$ diameter asphalt specimens in the laboratory is being explored. Next, experimental program presenting the results of the repeated creep tests has been explored in a detailed manner (for the asphalt specimens that have been prepared by Superpave gyratory compaction). Then the very positive effect of gyratory compaction on the prevention of strain accumulation in the specimen bodies when compared with dynamic Marshall compaction is explored in a detailed manner.

\section{Polypropylene Fiber Modification of Asphalt Mixtures}

Many valuable studies have been published about fiber modification of dense bituminous mixtures which can be found in a detailed manner in the relevant literature until $2008^{[27]}$. Tapkin has found that the addition of polypropylene fibers into the asphalt concrete on a dry basis alters the behaviour of the mixture in such a way that, Marshall stability values increase, flow values decrease and the fatigue life of the asphalt specimens increases significantly ${ }^{28}$. Tapkın et al. have also worked with the addition of polypropylene fibers to the asphalt concrete on a wet basis, and have shown that the most favourable and suitable polypropylene type was multifilament, $3 \mathrm{~mm}$ long (M-03 type) which increased the Marshall stability values by $20 \%$ as well as the stiffness of

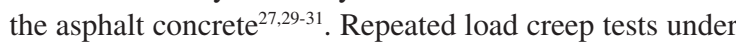
different loading patterns have also shown that the time to failure of fiber modified asphalt specimens under repeated creep loading at different loading patterns increased by 5-12 times versus reference specimens, which is a very significant improvement ${ }^{32}$. In another accompanying study, it was found that polypropylene modification of bituminous binders developed the physical and mechanical properties of the mixture and substantially improved its resistance to permanent deformation. Polypropylene modification also results in a saving of $30 \%$ in the amount of bitumen, resulting in considerable cost economy. Altogether the extra cost of using polypropylene fibers as a modifier is only $9.3 \%$ (for research purposes only, with no addition of technology and know-how, of course) but this cost is becoming much less, by diminishing the dependency on expensive imported modifiers and know-how ${ }^{18}$. This is a very important consideration for developing countries like Turkey ${ }^{18,27-32}$. There are also a number of other studies in the literature on different applications of polypropylene fiber modification of asphalt concrete in the last decade ${ }^{33-40}$.

\section{Creep Testing and the Relevant Literature Spanning the Last Two Decades}

Matthews and Monismith have performed unconfined creep tests at temperatures $25^{\circ} \mathrm{C}, 38^{\circ} \mathrm{C}$ and $49{ }^{\circ} \mathrm{C}$ which is a main departure from the published literature up to date in the testing temperature manner ${ }^{41}$. In another study by Mallick et al., in order to simulate the average pavement temperature throughout the United States, $60{ }^{\circ} \mathrm{C}$ of testing temperature was utilised. Also truck pressures were simulated by maintaining a $826.8 \mathrm{kPa}(120 \mathrm{psi})$ normal stress and $137.8 \mathrm{kPa}(20 \mathrm{psi})$ confining stress had been utilised for dynamic confined creep test. Moreover, a $1378 \mathrm{kPa}$ (200 psi) deviator stress along with a confining stress of $275.6 \mathrm{kPa}$ (40 psi) were used to simulate aircraft traffic $\mathrm{c}^{42}$. Ramsamooj and Ramadan had carried out creep tests at four stress levels under constant stresses of 150, 400, 650 and $900 \mathrm{kPa}^{43}$. Zhang et al. had utilised a material test system to conduct repeated creep tests. A deviator stress along with a confining stress was applied on a hot mix asphalt sample for 1 hour (3600 load cycles), with 0.1 second load duration and 
0.9 second rest period intervals ${ }^{44}$. Tashman et al. had carried out triaxial confined static creep test in determining the model parameters related to their studies. Both strength and creep tests were conducted at a temperature of $54.4^{\circ} \mathrm{C}\left(130{ }^{\circ} \mathrm{F}\right)^{45}$. This is again a significant departure from the routine testing protocol of $40{ }^{\circ} \mathrm{C}$ temperature ${ }^{16}$. A static constant load had been applied until "tertiary flow" occurred. The test had been stopped at the initiation of the tertiary creep zone in order to avoid damaging the linear variable differential transformer (LVDT); thus the experimental tertiary creep pattern could not have been recorded naturally ${ }^{45}$. Chen et al. had investigated the mechanical responses and modelling of rutting in flexible pavements. They had tested their asphalt specimens at two different temperatures of $40{ }^{\circ} \mathrm{C}$ and $60{ }^{\circ} \mathrm{C}$, and stresses of $240 \mathrm{kPa}$ during 60 minutes of static creep loading which was used to explain the mechanical behaviour of bituminous mixtures ${ }^{46}$. Goh \& You has revised the repeated creep testing ambient temperature in a different manner than only utilising $40{ }^{\circ} \mathrm{C}^{[47]}$. Vardanega et al. have used a very similar ambient temperature and loading pattern to Tapkin et al. ${ }^{27,29}$ in the studies that they have carried out (namely $50{ }^{\circ} \mathrm{C}$ and 0.5 (also 1.5) second loading and 1.5 (also 0.4 ) second unloading) depending on the argument which is also verified by the experience of QDMR (Queensland Department of Main Roads $)^{48}$. Chen et al. investigated the utilization of recycled brick powder as alternative filler in asphalt mixture. They had carried out static and dynamic creep tests using Universal Testing Machine (UTM) to apply constant stress to asphalt specimens. Their specimens were $100 \mathrm{~mm}$ in diameter and $100 \mathrm{~mm}$ in height. These specimens were tested at $60^{\circ} \mathrm{C}$ with a constant stress of $100 \mathrm{kPa}$ for 3600 seconds and unloaded for the recovery of deformations for 5400 seconds. Also dynamic creep tests were applied to the same axial stress level and same temperature ${ }^{49}$. Also in some studies carried out in the last five years that was utilising the "standard" procedure depicted in Zurich in 1977, the testing temperature had been chosen as $30{ }^{\circ} \mathrm{C}$ which was again a departure from this technique ${ }^{50-52}$.

\section{Utilisation of Superpave Gyratory Compactors in the Preparation of Asphalt Specimens}

In the last three decades, especially in the United States and in some parts of the rest of the world, with the advances in the Superpave practices, gyratory compactors have started to being used extensively especially for more realistic compaction effort simulations in the laboratory environment. In the study by Roberts et al., a review of the past, present, and future trends in asphalt mixture design are presented ${ }^{53}$. The very beneficial effects for the realistic simulation of the compaction on site in the laboratory environment by Superpave gyratory compactors is known and once more can be seen in the studies by various researchers that have been published in the last 13 years ${ }^{54-64}$. In all through these and the similar vast literature about the gyratory compaction studies published till date, limited studies about the $100 \mathrm{~mm}$ diameter specimens cored from $150 \mathrm{~mm}$ diameter gyratory compacted specimens for the preparation of laboratory prepared specimens have been discussed ${ }^{19-26}$. The vast majority of the other studies is about the physical and mechanical analyses of $150 \mathrm{~mm}$ diameter specimens prepared with Superpave gyratory compactors.

The very basic aim of this study is to investigate the rutting potential of polypropylene modified $100 \mathrm{~mm}$ diameter asphalt specimens prepared by using the Superpave gyratory compactor and to compare the obtained results with the previous studies of the lead author. As the Marshall design (opposing the assumptions of gyratory compaction via specimen dimensions) is utilising always $101.6 \mathrm{~mm}$ (rather $100 \mathrm{~mm}$ for practical purposes) diameter asphalt specimens, it is really important to compare the results of the mechanical testing (repeated creep test results) results obtained by the previous studies of the lead author with a more realistic compaction simulation approach ${ }^{18,27-31}$.

According to Jackson \& Czor, due to increasing traffic levels and vehicle wheel loads, it has become necessary to improve the effectiveness and efficiency of the design of hot mix asphalt. The Superpave gyratory compactor makes use of a $150 \mathrm{~mm}$ diameter cylindrical mould to produce specimens for the design and evaluation under the Superpave system. The objective of their study was to explore the potential for using a $100 \mathrm{~mm}$ diameter mould to produce test specimens in the laboratory. Based on the findings of their study, it has been recommended to the Tennessee Department of Transportation (TDOT) that it is feasible to use $100 \mathrm{~mm}$ diameter specimens in lieu of the $150 \mathrm{~mm}$ diameter specimens for quality assessment/quality control acceptance and verification testing of hot mix asphalt. According to the researchers, it should be noted that this recommendation is limited to mixes with a maximum aggregate size of $25.4 \mathrm{~mm}$ or less. Some of the potential advantages associated with the use of the 100-mm-diameter cylinder mould include the following: a) The required sample size is reduced by $400 \%$; thus, time of preparation, storage space, and transportation of materials are similarly reduced; b) It is possible to conduct conventional laboratory testing with the $100 \mathrm{~mm}$ diameter specimen; and c) The majority of surface mix designs in Tennessee make use of $25.4 \mathrm{~mm}$, or smaller maximum aggregate size; thus, the larger $150 \mathrm{~mm}$ mould is often not necessary to be in compliance with ASTM and AASHTO requirements ${ }^{65}$.

According to the above discussion, all throughout the study, $100 \mathrm{~m}$ specimens were fabricated with an IPC Servopac Gyratory compactor in the experiments that have been carried out in the laboratory environment ${ }^{66}$.

\section{Experimental Analyses}

\subsection{Material properties}

Throughout the study, continuous aggregate gradation has been used to fit the gradation limits for wearing course Type 2 set by General Directorate of Turkish Highways ${ }^{67}$. The aggregate was calcareous type crushed stone obtained from a local quarry. 50/70 penetration bitumen was obtained from a local refinery and was used for preparation of the Marshall specimens. Physical properties of the bitumen samples are given in Table 1 . The physical properties of coarse and fine aggregates are given in Tables 2 and 3 . The apparent specific gravity of filler is $2739 \mathrm{~kg} \cdot \mathrm{m}^{-3}$. 
The mixture gradation and gradation limits are given in Table 4.

In the wet basis modification procedure of the asphalt concrete specimens, standard 50/70 penetration bitumen was modified by utilising polypropylene fibers. The fibers were premixed with bitumen using a standard mixer at 500 revolutions per minute for two hours. The mixing temperature was around $165-170{ }^{\circ} \mathrm{C}^{[68]}$. For the sake of testing reasons, the reference bitumen samples were also subjected to the same temperature to equalise the oxidation and aging effects of two hours of heat effect utilised in polypropylene modification. According to the workability criteria, M-03 type fibers were used all throughout the testing and due to comparison reasons with the lead author's previous studies ${ }^{27,29-31}, 3 \%$ fiber content was utilised as the optimal addition amount. With these amounts, polypropylene fibers melt in bitumen and bitumen forms a continuous phase for polypropylene particles. The physical properties of the polypropylene fiber based bitumen samples with $3 \%$ fiber content are given in Table 5 .

The performance characteristics, such as penetration, penetration index, ductility, loss on heating, specific gravity, and softening point of the polypropylene fiber modified bitumen samples were greatly improved as compared to reference specimens given in Table 5. Also the increase in Brookfield viscosity values is as expected. Therefore,

Table 1. Physical properties of the reference bitumen.

\begin{tabular}{ccc}
\hline Property & Test value & Standard \\
\hline Penetration at $25^{\circ} \mathrm{C}(1 / 10 \mathrm{~mm})$ & 68.35 & ASTM D 5-97 \\
Penetration Index & -0.26 & - \\
Ductility at $25^{\circ} \mathrm{C}(\mathrm{cm})$ & $>100$ & ASTM D 113-99 \\
Viscosity at $135^{\circ} \mathrm{C}(\mathrm{Pa} \mathrm{s})$ & 0.335 & ASTM D 4402 \\
Loss on heating $(\%)$ & 0.0572 & ASTM D 6-80 \\
Specific gravity at $25^{\circ} \mathrm{C}\left({\left.\mathrm{kg} \cdot \mathrm{m}^{-3}\right)}\right)$ & 1028 & ASTM D 70-76 \\
Softening point ${ }^{\circ} \mathrm{C}$ & 50.67 & ASTM D 36-95 \\
Flash point ${ }^{\circ} \mathrm{C}$ & 312 & ASTM D 92-02 \\
Fire point ${ }^{\circ} \mathrm{C}$ & 344 & ASTM D 92-02 \\
\hline
\end{tabular}

Table 2. Physical properties of coarse aggregates.

\begin{tabular}{ccc}
\hline Property & Test value & Standard \\
\hline Bulk specific gravity $\left(\mathrm{kg} \cdot \mathrm{m}^{-3}\right)$ & 2698 & ASTM C 127-04 \\
S.S.D. specific gravity $\left(\mathrm{kg} \cdot \mathrm{m}^{-3}\right)$ & 2703 & ASTM C 127-04 \\
Apparent specific gravity $\left(\mathrm{kg} \cdot \mathrm{m}^{-3}\right)$ & 2712 & ASTM C 127-04 \\
Water absorption $(\%)$ & 0.191 & ASTM C 127-04 \\
\hline
\end{tabular}

Table 3. Physical properties of fine aggregates.

\begin{tabular}{ccc}
\hline Property & Test value & Standard \\
\hline Bulk specific gravity $\left(\mathrm{kg} \cdot \mathrm{m}^{-3}\right)$ & 2684 & ASTM C 128-04 \\
$\begin{array}{c}\text { S.S.D. specific gravity }\left(\mathrm{kg} \cdot \mathrm{m}^{-3}\right) \\
\text { Apparent specific gravity } \\
\quad\left(\mathrm{kg} \cdot \mathrm{m}^{-3}\right)\end{array}$ & 2710 & ASTM C 128-04 \\
$\begin{array}{c}\text { Water absorption }(\%) \\
\text { ASTM C 128-04 }\end{array}$ & 0.962 & ASTM C 128-04 \\
\hline
\end{tabular}

the addition of $3 \%$ of M-03 type fibers clearly shows the decrease in temperature susceptibility of the reference bitumen (as shown by the eminent increase in the penetration index of polypropylene modified bitumen samples) providing the most significant effect on the properties of resultant asphalt concrete mixtures as an increase in the stiffness values. For the next step of experiments, the optimum bitumen content was taken as $5 \%$ for the sake of comparison purposes with the previously prepared and mechanically tested Marshall specimens ${ }^{27,29-31}$.

\subsection{Test setup and gyratory compaction procedures undertaken}

All through the tests, an IPC Servopac gyratory compactor has been used to produce $100 \mathrm{~mm}$ asphalt specimens ${ }^{66}$. In order to be able to produce these specimens which have been tested in an extensive manner in the previous studies of the leading author to show the very positive effects of gyratory compaction, more than 800 specimens have been prepared and tested ${ }^{27,29-31}$. In Table 6, the very final comparison of the physical and mechanical properties of the reference and $3 \%$ M-03 type polypropylene modified specimens are given. When this table, which is representing the values of more than 48 specimens respectively is examined, it can be clearly seen that the physical and mechanical properties are nearly equal to each other (except flow values as the compaction mechanism of gyratory compactors is extremely different than the usual Marshall procedure). As the usual practice, $600 \mathrm{kPa}$ ram pressure and $1.25^{\circ}$ gyratory angle have been used in the

Table 4. Type 2 wearing course gradation ${ }^{67}$

\begin{tabular}{cccc}
\hline $\begin{array}{c}\text { Sieve size } \\
(\mathbf{m m})\end{array}$ & $\begin{array}{c}\text { Gradation limits } \\
(\boldsymbol{\%})\end{array}$ & $\begin{array}{c}\text { Passing } \\
(\boldsymbol{\%})\end{array}$ & $\begin{array}{c}\text { Retained } \\
(\boldsymbol{\%})\end{array}$ \\
\hline 12.7 & 100 & 100 & 0 \\
9.52 & $80-100$ & 90 & 10 \\
4.76 & $55-72$ & 63.5 & 26.5 \\
2.00 & $36-53$ & 44.5 & 19.0 \\
0.42 & $16-28$ & 22 & 22.5 \\
0.177 & $8-16$ & 12 & 10.0 \\
0.074 & $4-10$ & 7 & 5 \\
Pan & - & - & 7 \\
\hline
\end{tabular}

Table 5. Physical properties of the polypropylene modified bitumen samples.

\begin{tabular}{ccc}
\hline Property & Test Value & Standard \\
\hline Penetration at $25^{\circ} \mathrm{C}(1 / 10 \mathrm{~mm})$ & 32.02 & ASTM D 5-97 \\
Penetration Index & 1.639 & - \\
Ductility at $25^{\circ} \mathrm{C}(\mathrm{cm})$ & 56.1 & ASTM D 113-99 \\
Viscosity at $135^{\circ} \mathrm{C}(\mathrm{Pa} \mathrm{s})$ & 0.725 & ASTM D 4402 \\
Loss on heating $(\%)$ & 0.031 & ASTM D 6-80 \\
Specific gravity at $25^{\circ} \mathrm{C}\left(\mathrm{kg} \cdot \mathrm{m}^{-3}\right)$ & 1018 & ASTM D 70-76 \\
Softening point $\left({ }^{\circ} \mathrm{C}\right)$ & 69.30 & ASTM D 36-95 \\
Flash point $\left({ }^{\circ} \mathrm{C}\right)$ & 279 & ASTM D 92-02 \\
Fire point $\left({ }^{\circ} \mathrm{C}\right)$ & 332 & ASTM D 92-02 \\
\hline
\end{tabular}


Table 6. Average physical and mechanical properties of the specimens prepared with two different compaction techniques.

\begin{tabular}{ccccccccc}
\hline $\begin{array}{c}\text { Polypropylene } \\
\text { amount } \\
(\%)\end{array}$ & $\begin{array}{c}\text { Unit } \\
\text { weight } \\
\left(\mathbf{k g . m}^{-3}\right)\end{array}$ & $\begin{array}{c}\text { Air voids } \\
(\boldsymbol{\%})\end{array}$ & $\begin{array}{c}\text { Vf } \\
(\boldsymbol{\%})\end{array}$ & $\begin{array}{c}\text { V.M.A. } \\
(\boldsymbol{\%})\end{array}$ & $\begin{array}{c}\text { Stability } \\
(\mathbf{k g})\end{array}$ & $\begin{array}{c}\text { Flow } \\
(\mathbf{m m})\end{array}$ & $\begin{array}{c}\text { Marshall } \\
\text { quotient } \\
\left(\mathbf{k g . m m}^{-1}\right)\end{array}$ & $\begin{array}{c}\text { Blows \& } \\
\text { Gyration } \\
\text { number }\end{array}$ \\
\hline 0.0 (Marshall) & 2465 & 3.443 & 76.990 & 14.919 & 1294.355 & 3.463 & 376.899 & 50 \\
0.0 (SGC) & 2456 & 3.219 & 77.896 & 14.608 & 1263.714 & 4.195 & 301.651 & 40 \\
3.0 (Marshall) & 2432 & 4.707 & 70.710 & 16.033 & 1542.140 & 2.982 & 523.329 & 50 \\
3.0 (SGC) & 2417 & 4.639 & 70.863 & 15.957 & 1547.458 & 3.526 & 446.805 & 33 \\
\hline
\end{tabular}

gyratory compaction and the optimal gyration number for $100 \mathrm{~mm}$ specimens has been found 40 for reference and 33 for polypropylene modified specimens for the similar and specific type of aggregate sources, bitumen, aggregate gradation, mix proportioning, modification technique and laboratory conditions ${ }^{69}$. In order to determine this optimal gyration number, very intense testing has been carried out. The procedure followed through these studies is as follows:

- Target air voids concept has been utilised in a way that the air void values should have been between $3 \%$ and $5 \%$ for both reference and polypropylene modified specimens according to the acting standards ${ }^{67}$;

- Table 6 was the guide in the search for an optimal gyration number of both types of specimens. The Marshall design "air void" values were tried to be reached with the aid of the software embedded in the IPC Servopac gyratory compactor (target air voids content $)^{66}$. By the aid of this software, gyration angle, specimen height, air voids, unit weight, shear stress and vertical stress can be monitored online. Air voids value was the main parameter that has been monitored in a detailed manner;

- Although air voids values were monitored in a very rigorous manner, some other studies were also carried out in a way that the gyration numbers were changed between 30 and 135 (in increments of 5) in order to be able to validate the physical and mechanical variances between the different gyration numbers (for both reference and polypropylene modified specimens). The air voids, voids filled with asphalt, voids in mineral aggregate, unit weight, stability, flow and Marshall Quotient values have been continuously checked with the previously prepared Marshall specimens' properties ${ }^{69}$; and

- Finally, the optimal gyration number for $100 \mathrm{~mm}$ specimens has been found 40 for reference and 33 for polypropylene modified specimens for the similar and specific type of aggregate sources, bitumen, aggregate gradation, mix proportioning, modification technique and laboratory conditions.

\subsection{Repeated load creep testing with the $100 \mathrm{~mm}$ gyratory compactor specimens}

A completely different loading pattern, loading stress level and testing temperature than the previous studies have been adopted ${ }^{27}$. First of all, the testing temperature was chosen as $50^{\circ} \mathrm{C}$ to simulate actual in-situ conditions $s^{27,29}$. An axial stress, $\sigma$, of $500 \mathrm{kPa}$ was applied to the specimens until the specimen enters the tertiary creep region up to nearly a failure point to simulate the actual in-place conditions in a realistic manner ${ }^{27,32}$. Also it has to be mentioned that, in today's modern pavement engineering practices, there are also other bitumen modifying agents than polypropylene fibers which need to be tested in actual stress levels in order to show the very positive contribution of these modifiers to the genuine mechanical behaviour of polymer modified dense bituminous mixtures. Repeated creep tests have been performed in order to log the accumulation mechanisms of the developing strains in the specimen body, or in other words rutting potential. The creep deformation of $100 \mathrm{~mm}$ gyratory compactor specimens was measured as a function of rectangular pulse counts or rather time. The load on the specimens was uniaxial and dynamic, which was representing the repeated application of axle loads. The dimensions of asphalt specimens were approximately the same for nearly all of the specimens. Therefore, a unity in the dimensions was standardized. Prior to testing, the specimens were put into the chamber for 24 hours in order to have the uniform temperature distribution. All of the tests were carried at $50{ }^{\circ} \mathrm{C}$. For controlled temperature testing, the specimen's skin and core temperature were estimated by transducers inserted in a dummy specimen and located near the specimen under test ${ }^{32}$. To understand the behaviour of the asphalt specimens under different loading patterns, different constant stress values were chosen. These values were 100 , 207 and $500 \mathrm{kPa}$. As polypropylene modification was carried out, utilizing lower stress values like 100 and $207 \mathrm{kPa}$ was not feasible, since under such loading the tertiary creep region could not be observed within a reasonable period of time. Therefore, in order to be able to differentiate between the reference and fiber-reinforced samples, a real destructive loading level of $500 \mathrm{kPa}$ (approximately $73 \mathrm{psi}$ ) was chosen as the standard stress value which is a main departure from the published pioneering literature of the rule of thumbs about creep testing ${ }^{1-7}$. This value very well represents the actual tire pressure of a loaded truck. The specimen strain during the pulsed loading stage of the test were measured in the same axis as the applied stress using two linear variable displacement transducers (LVDTs). The applied force was

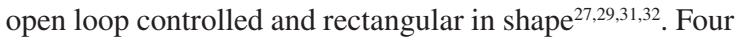
specimens were tested for each loading pattern. Load periods were chosen as $500 \mathrm{~ms}$ for all of the specimens and the rest periods were 500, 1000, 1500 and $2000 \mathrm{~ms}$, respectively. $500 \mathrm{~ms}-500 \mathrm{~ms}$ loading pattern represents the most severe loading pattern that represents the dynamic application of very fast moving vehicles on a roadway section on a minimum recovery time basis. $500 \mathrm{~ms}-1000 \mathrm{~ms}$ loading 
pattern presents a dynamic application of slower moving vehicles than the previous one. $500 \mathrm{~ms}-1500 \mathrm{~ms}$ loading pattern presents a normal speed moving vehicle on that same section which is also analogous to the standard load pattern of the dynamic creep test of Australian standards but developed individually by the lead author ${ }^{70} .500 \mathrm{~ms}-2000 \mathrm{~ms}$ loading pattern presents a slower speed moving vehicle to simulate the elastic recovery of the specimens in a better manner under repetition of standard axle loads on site and complete the most general picture of the variable rest times.

The physical properties and loading conditions of 16 reference and $16 \mathrm{M}-03$ type polypropylene fiber-modified specimens are given in Table 7 (Here RC stands for repeated creep, RC (P) stands for polypropylene fiber reinforced specimens, 0505 stands for $500 \mathrm{~ms}$ load $500 \mathrm{~ms}$ rest period). At this point, it has to be mentioned about the fact that due to the end effects concern, a certain diameter to height ratio is necessary for the accuracy of the repeated tests. A specimen with a dimension of $100 \mathrm{~mm}$ diameter by $200 \mathrm{~mm}$ height is usually recommended for the creep tests to minimize edge effects ${ }^{8}$. Therefore, ideally, an aspect ratio of $2: 1$ is suggested for most axial loading tests. But due to limitation of compacting equipment, it is very difficult to prepare lab specimens with an aspect ratio of 2:1 that also satisfy the minimum diameter requirement for nominal maximum aggregate size ${ }^{71}$. Witczak et al. found that for asphalt mixtures, $100 \mathrm{~mm}$ diameter and $150 \mathrm{~mm}$ height specimens would give satisfactory results for both small strain (dynamic modulus) and large strain (creep) tests ${ }^{72}$. However, it has to be kept in mind that edge effects do occur on the roadway, for example when layers with large aggregate are used. So there may be some advantage in simulating these edge effects during testing (this concept should not be thrown out of minds simply as being theoretically incorrect). Since it is not easy to fabricate a specimen with a 1:2 diameter to height ratio in a laboratory environment, specimens with varied

Table 7. Physical properties and loading conditions of reference and M-03 type polypropylene fiber-modified specimens prepared utilizing gyratory compaction.

\begin{tabular}{|c|c|c|c|c|c|c|}
\hline $\begin{array}{c}\text { Specimen } \\
\text { number }\end{array}$ & $\begin{array}{l}\text { Height } \\
(\mathbf{m m})\end{array}$ & $\begin{array}{c}\text { Gyration } \\
\text { number }\end{array}$ & $\begin{array}{c}\text { V.M.A } \\
(\%)\end{array}$ & $\begin{array}{l}\mathbf{V f} \\
(\%)\end{array}$ & $\begin{array}{c}\text { Air Voids } \\
(\%)\end{array}$ & $\begin{array}{c}\text { Unit weight } \\
\left(\mathrm{kg}^{\left.-\mathrm{m}^{-3}\right)}\right.\end{array}$ \\
\hline $\mathrm{RC} 0505 \mathrm{~A}$ & 61.45 & 29 & 14.908 & 76.039 & 3.560 & 2447 \\
\hline RC0505B & 61.48 & 33 & 14.902 & 76.074 & 3.553 & 2447 \\
\hline $\mathrm{RC} 0505 \mathrm{C}$ & 61.45 & 42 & 14.229 & 80.305 & 2.790 & 2467 \\
\hline RC0505D & 61.44 & 36 & 14.209 & 80.433 & 2.768 & 2467 \\
\hline $\mathrm{RC} 0510 \mathrm{~A}$ & 61.44 & 37 & 14.340 & 79.580 & 2.915 & 2464 \\
\hline RC0510B & 61.50 & 38 & 14.188 & 80.573 & 2.744 & 2468 \\
\hline RC0510C & 61.46 & 39 & 14.105 & 81.124 & 2.650 & 2470 \\
\hline RC0510D & 61.44 & 41 & 14.427 & 79.021 & 3.014 & 2461 \\
\hline $\mathrm{RC} 0515 \mathrm{~A}$ & 61.44 & 34 & 14.518 & 78.440 & 3.117 & 2458 \\
\hline RC0515B & 61.46 & 37 & 14.383 & 79.299 & 2.965 & 2462 \\
\hline $\mathrm{RC} 0515 \mathrm{C}$ & 61.48 & 31 & 14.488 & 78.628 & 3.084 & 2459 \\
\hline RC0515D & 61.50 & 40 & 14.429 & 79.006 & 3.017 & 2461 \\
\hline $\mathrm{RC} 0520 \mathrm{~A}$ & 61.48 & 41 & 14.479 & 78.686 & 3.073 & 2460 \\
\hline RC0520B & 61.48 & 42 & 14.737 & 77.073 & 3.366 & 2452 \\
\hline RC0520C & 61.45 & 42 & 14.560 & 78.172 & 3.166 & 2457 \\
\hline RC0520D & 61.47 & 42 & 14.410 & 79.130 & 2.994 & 2462 \\
\hline RCP0505A & 62.56 & 27 & 16.070 & 70.263 & 4.766 & 2414 \\
\hline RCP0505B & 62.61 & 24 & 16.084 & 70.190 & 4.782 & 2413 \\
\hline $\mathrm{RCP} 0505 \mathrm{C}$ & 62.61 & 35 & 16.121 & 69.994 & 4.825 & 2412 \\
\hline RCP0505D & 62.62 & 26 & 16.118 & 70.012 & 4.821 & 2412 \\
\hline RCP0510A & 62.61 & 25 & 16.167 & 69.760 & 4.876 & 2411 \\
\hline RCP0510B & 62.62 & 38 & 16.127 & 69.968 & 4.831 & 2412 \\
\hline RCP0510C & 62.60 & 25 & 16.129 & 69.957 & 4.833 & 2412 \\
\hline RCP0510D & 62.57 & 31 & 16.110 & 70.052 & 4.812 & 2413 \\
\hline RCP0515A & 62.59 & 28 & 15.938 & 70.954 & 4.617 & 2418 \\
\hline RCP0515B & 62.62 & 24 & 15.980 & 70.732 & 4.665 & 2416 \\
\hline RCP0515C & 62.58 & 31 & 15.934 & 70.976 & 4.612 & 2418 \\
\hline RCP0515D & 62.61 & 28 & 15.974 & 70.764 & 4.658 & 2417 \\
\hline RCP0520A & 62.62 & 24 & 15.913 & 71.089 & 4.588 & 2418 \\
\hline RCP0520B & 62.56 & 29 & 15.870 & 71.318 & 4.539 & 2420 \\
\hline RCP0520C & 62.56 & 29 & 15.882 & 71.255 & 4.553 & 2419 \\
\hline RCP0520D & 62.61 & 29 & 15.860 & 71.370 & 4.528 & 2420 \\
\hline
\end{tabular}


dimensions have been used in creep tests just as the aspect ratio of approximately 0.6 in order to be tested in UTM 5-P under repeated creep loading ${ }^{8}$. Also the importance of these kinds of specimens produced is they are completely "undisturbed" specimens.

In the repeated creep test the accumulated axial strain, the resilient axial strain, peak vertical stress, resilient modulus and creep stiffness were calculated by the following Equations $^{73}$ :

$\varepsilon_{c}=\frac{\left(L 3_{n}-L_{1}\right)}{G}$

$\varepsilon_{r}=\frac{\left(L 2_{n}-L 3_{n}\right)}{\left(G-\left(L 3_{n}-L 1\right)\right)}$

$\sigma=\frac{F}{A}$

$E_{r}=\frac{\sigma}{\varepsilon_{r}}$

$E_{c}=\frac{\sigma}{\varepsilon_{c}}$

where $\varepsilon_{c}$ is the accumulated axial strain $(\mu \varepsilon), \varepsilon_{\mathrm{r}}$ is the resilient axial strain $(\mu \varepsilon), \sigma$ is the peak vertical stress $(\mathrm{kPa})$, L3 is the final displacement level of the transducer for pulse 'n' just prior to the application of the stress for pulse ' $\mathrm{n}+1$ ' (mm), L1 is the initial zero reference displacement of the transducers $(\mathrm{mm}), \mathrm{G}$ is the initial specimen length $(\mathrm{mm}), \mathrm{L} 2$ is the maximum displacement of the transducers with stress applied for pulse 'n', $F$ is the peak vertical force $(\mathrm{N}), A$ is the cross-sectional area of the specimen $\left(\mathrm{mm}^{2}\right)$, $\mathrm{E}_{\mathrm{r}}$ is the resilient modulus $(\mathrm{MPa}), \mathrm{E}_{\mathrm{c}}$ is the creep stiffness or modulus (MPa).

Asphalt concrete under constant stress condition exhibits a typical deformation characteristic which can be explained in four stages as shown in Figure 1. These are: a) Instantaneous elastic and/or non-elastic deformation; with the application of load, there is an immediate deformation, which is explained by the behaviour of spring element in the rheological model. Upon the removal of the load through this stage, a portion of the deformation is recovered instantaneously. The amount of recovery is not necessarily

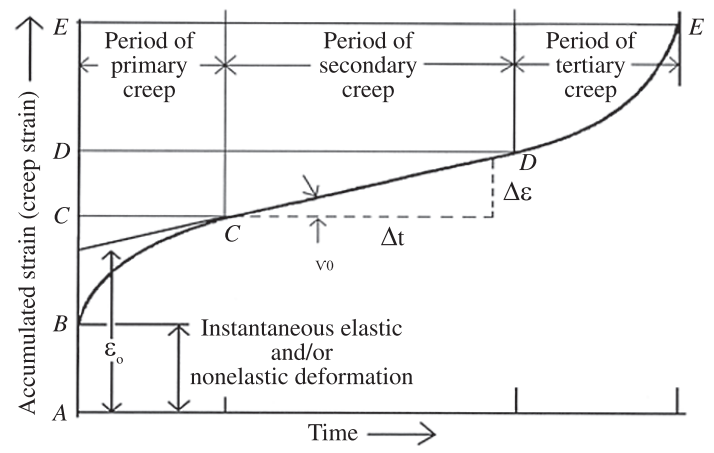

Figure 1. Typical deformation characteristic of asphalt concrete under constant stress condition in four stages. equal to the instantaneous deformation that has occurred due to the application of the initial load; b) Primary creep: if the load on the system is not removed, the material deforms further, but with a decreasing rate, which is explained by the deformation characteristics of the Kelvin body in the system. Observed deformation at this stage has both recoverable and unrecoverable portions; c) Secondary creep: at this region the slope of deformation is linear, which is represented as the deformation of the dashpot of the Maxwell body in the system. The deformation that exhibits at this stage is unrecoverable; d) Tertiary creep: this stage represents the complete plastic failure of the material. In this stage deformation has an accelerated increasing rate. Witczak et al. defined the flow number as the loading-cycle number where tertiary deformation starts ${ }^{74}$. The flow number is an indication of the start of the failure of the asphalt specimens of the repeated creep test. In this study, the specimens have been tested to a point where the creep stiffness have dropped to a certain level through the tests which are $10 \mathrm{MPa}$. In most cases, this value has been accepted as the termination level.

The results of the repeated creep tests of $100 \mathrm{~mm}$ gyratory compactor specimens are given in Figures 2-9. The first graphs present the accumulated strain versus pulse counts and the second graphs describe the creep stiffness versus pulse counts of the repeated creep test results. These graphs show the general trend of the four different specimens under the specified loading and temperature conditions. The

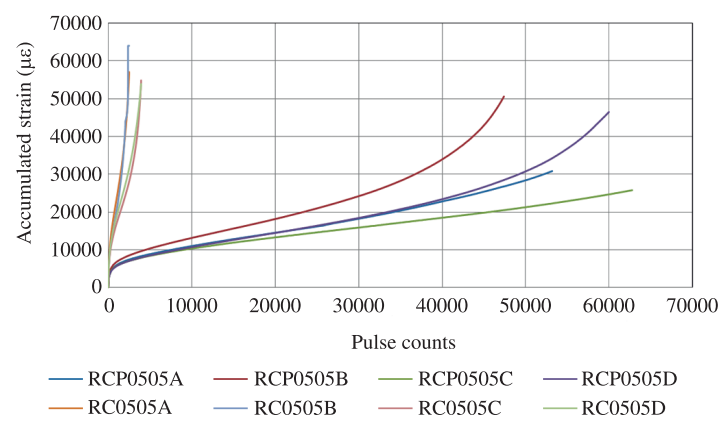

Figure 2. Accumulated strain vs. pulse counts of specimens with a loading pattern of $500 \mathrm{~ms}$ load $-500 \mathrm{~ms}$ rest period $(100 \mathrm{~mm}$ diameter gyratory compactor specimens).

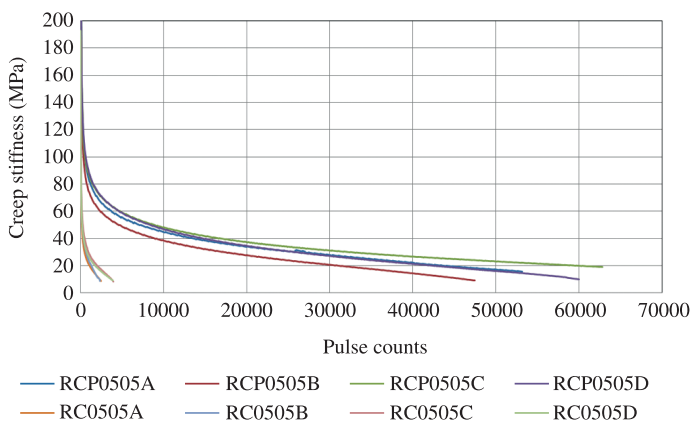

Figure 3. Creep stiffness vs. pulse count of specimens with a loading pattern of $500 \mathrm{~ms}$ load - $500 \mathrm{~ms}$ rest period (100 mm diameter gyratory compactor specimens). 
applied constant stress was $500 \mathrm{kPa}$ and the test temperature was $50{ }^{\circ} \mathrm{C}$ for all the experiments.

The life of fiber-reinforced specimens under repeated creep tests are approximately 18 times longer than the control specimens under the same testing conditions (Figures 2 and 3). This is a very significant difference showing the very positive effect of polypropylene fiber modification utilized in gyratory compaction. Figure 2 illustrates the control specimens are entering to the tertiary stage of creep only at around 2000 pulse counts; this loading rate corresponds to the primary creep stage for the polypropylene fiber modified specimens. Fiber modified specimens reach their tertiary creep stage around pulse counts of 30,000 and more. At the end of the repeated creep tests, the control specimens have a total collapse, while the fiber reinforced specimens did not show any visible sign of failure until then. The mechanical behaviour of asphalt specimens prepared by gyratory compaction exhibits a very similar behaviour when the reference and polypropylene modified specimens are concerned groupwise except RC0505B, RCP050A and RCP0505C. For the RC0505B specimen, the repeated testing had been continued until the specimen failed completely and because of this reason the accumulated strain values well reached above $64000 \mu \varepsilon$. RCP0505A and RCP0505C had shown a different rheological behaviour than the specimens as the other two specimens, RCP0505B and RCP0505D, had entered tertiary creep region but these two specimens were in secondary creep region. The explanation of this basically depends on the physical property differences between these specimens which can be visualised in Table 7. Because of this reason, the test had been interrupted around 60000 pulses which were in fact 16 hours 40 minutes of testing time. For the calculation of the "life of specimens" under creep test, for all of the specimens, reaching a creep stiffness value of less than $10 \mathrm{MPa}$ was accepted for the termination of the repeated creep tests.

Creep stiffness values drop to a certain level through the tests which are $10 \mathrm{MPa}$. This level can be accepted as the termination of the test. For both specimen types, the termination stiffness values are the same, but the pattern of the decrease in these values shows very different behaviours. When the control specimens fail, the creep stiffness of the fiber reinforced specimens have only dropped to $30 \%$ values of their original values. In addition, the initial creep stiffness values of the fiber modified specimens are correspondingly higher vs. the control specimens, as can be expected from the plastomeric modifying effects of polypropylene. But because of the operating conditions of the UTM-5P system, an exact figure cannot be determined. The same argument above which was stated for the accumulated strain is also valid for the creep stiffness analyses.

The corresponding graphs for the control and fiber modified specimens tested at the $500 \mathrm{~ms}$ load - $1000 \mathrm{~ms}$ rest pattern is given in Figures 4 and 5 .

The life of the fiber reinforced specimens under this pattern of loading and unloading is approximately eight times longer vs. the control specimens. $500 \mathrm{~ms}$ load $-500 \mathrm{~ms}$ rest periods loading pattern has a life approximately 2.2 times longer than the $500 \mathrm{~ms}$ load $-1000 \mathrm{~ms}$ rest periods loading pattern. This clearly shows the detrimental effect of longer load exposure on the performance of the asphalt concrete under repeated creep testing. That is, this loading pattern is less severe than $500 \mathrm{~ms}$ load $-500 \mathrm{~ms}$ rest loading pattern. The reason for this is the second loading pattern, which can be visualized through Figures 4 and 5, does not allow sufficient time for the viscoelastic rebound potential of the specimen to occur. Thus, when each subsequent load cycle is applied, the loading deformation of the specimen is reduced. Simple physics would suggest that the "work" done to the specimen would be reduced as the force is applied over a shorter distance via $500 \mathrm{~ms}$ load - $500 \mathrm{~ms}$ rest loading pattern ${ }^{48}$. The control specimens are less affected by this second type of loading pattern as their lives are much shorter vs. the fiber modified specimens. The mechanical behaviour of asphalt specimens prepared by gyratory compaction exhibits a very similar behaviour when the reference and polypropylene modified specimens are concerned groupwise except RC0510C, RCP0510A and RCP0510B. The explanation of this basically depends on the physical property differences between these specimens which can be visualised in Table 7 .

In respect to the creep stiffness values, the observation can be made that while the control specimens fail, the fiber modified specimen's creep stiffness values have only dropped approximately to $28 \%$ of their original values. The same argument above which was stated for the accumulated strain is also valid for the creep stiffness analyses.

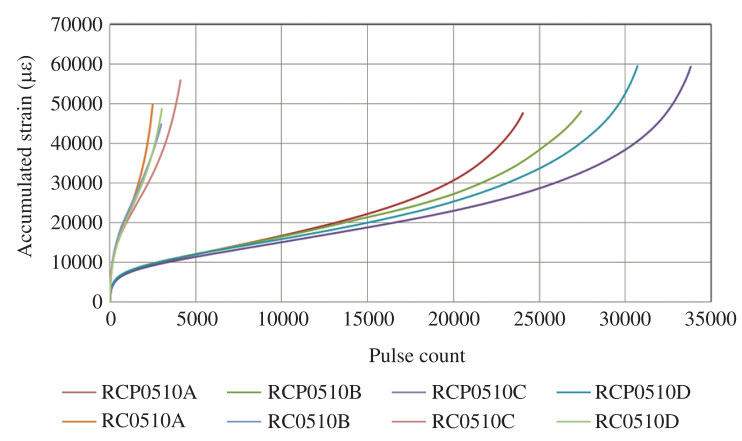

Figure 4. Accumulated strain vs. pulse counts of specimens with a loading pattern of $500 \mathrm{~ms}$ load $-1000 \mathrm{~ms}$ rest period $(100 \mathrm{~mm}$ diameter gyratory compactor specimens).

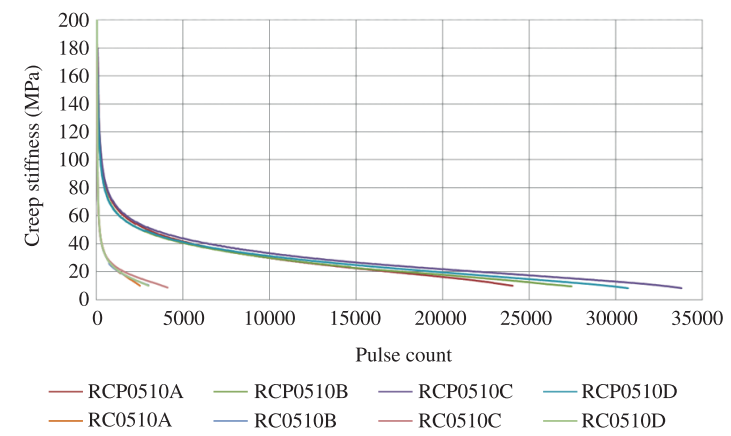

Figure 5. Creep stiffness vs. pulse count of specimens with a loading pattern of $500 \mathrm{~ms}$ load $-1000 \mathrm{~ms}$ rest period $(100 \mathrm{~mm}$ diameter gyratory compactor specimens). 
The corresponding graphs of the control and fiber reinforced specimens for the $500 \mathrm{~ms}$ load $-1500 \mathrm{~ms}$ rest periods are given in Figures 6 and 7.

The lives of fiber modified specimens are approximately 10.5 times longer than the lives of the control specimens especially arising from the fact that gyratory compaction is much more efficient in the preparation of more stable mixes from the rutting susceptibility point of view ${ }^{69}$. Similar to the previous loading patterns, when the control specimens reach their tertiary creep stage, the fiber modified specimens are in their primary creep stage. The mechanical behaviour of asphalt specimens prepared by gyratory compaction exhibits a very similar behaviour when the reference and polypropylene

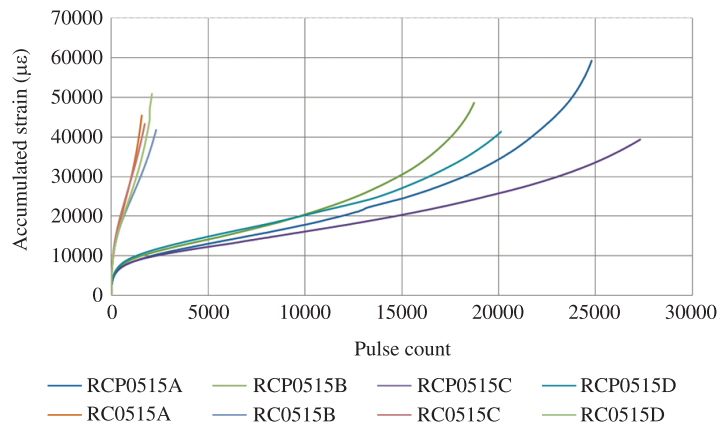

Figure 6. Accumulated strain vs. pulse counts of specimens with a loading pattern of $500 \mathrm{~ms}$ load - $1500 \mathrm{~ms}$ rest period $(100 \mathrm{~mm}$ diameter gyratory compactor specimens).

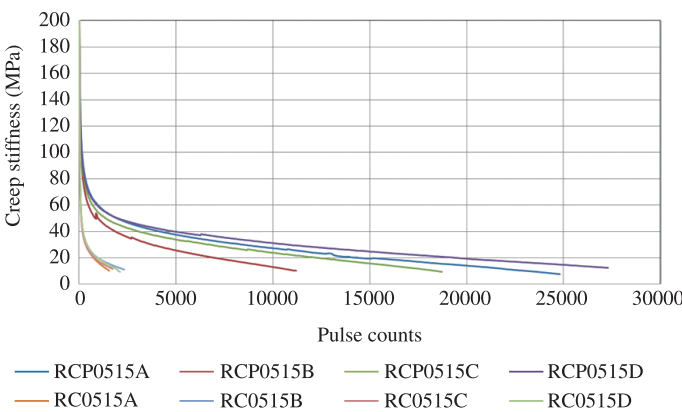

Figure 7. Creep stiffness vs. pulse count of specimens with a loading pattern of $500 \mathrm{~ms}$ load - $1500 \mathrm{~ms}$ rest period (100 mm diameter gyratory compactor specimens).

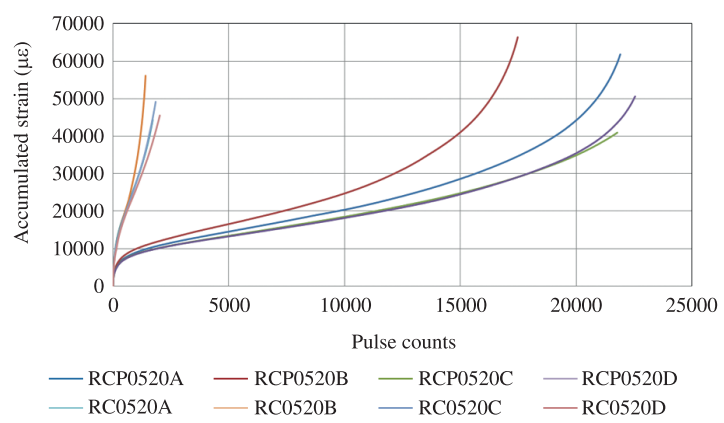

Figure 8. Accumulated strain vs. pulse counts of specimens with a loading pattern of $500 \mathrm{~ms}$ load - $2000 \mathrm{~ms}$ rest period $(100 \mathrm{~mm}$ diameter gyratory compactor specimens). modified specimens are concerned groupwise except RC0515D and RCP0515A. The explanation of this basically depends on the physical property differences with respect to other specimens which can be visualised in Table 7. The same argument above which was stated for the accumulated strain is also valid for the creep stiffness analyses.

The accumulated strain vs. pulse counts and the creep stiffness vs. pulse counts of the control and modified specimens for the $500 \mathrm{~ms}$ load $-2000 \mathrm{~ms}$ rest periods are given in Figures 8 and 9. The main difference of this loading pattern is related to considerably longer rest periods. This can help to model the traffic pattern where the repetition of the axle loads is not as destructive as $500 \mathrm{~ms}$ load - $500 \mathrm{~ms}$ rest periods which presents a slower speed moving vehicle to simulate the elastic recovery of the specimens in a better manner under repetition of standard axle loads on site (i.e. resulting in 12 times longer lives than the control specimens). The mechanical behaviour of asphalt specimens prepared by gyratory compaction exhibits a very similar behaviour when the reference and polypropylene modified specimens are concerned groupwise except RC0520B and RCP0520B. The explanation of this basically depends on the physical property differences between these specimens which can be visualised in Table 7 . The same argument above which was stated for the accumulated strain is also valid for the creep stiffness analyses.

From all of the above discussions, it can be concluded that as the rest time increases, the rate of strain accumulation in the specimens bodies also increases. This is primarily because of the detrimental effect of the rest period on the specimens as when the rest period increases, the permanent deformations start to act in a more pronounced manner. These phenomena can also be explained by another manner that, in the $500 \mathrm{~ms}$ load $-500 \mathrm{~ms}$ rest period pattern, the "toughness" effect comes into the scene and making the asphalt specimen in a way more "rigid". In materials science, toughness, as a general term, can be defined as the ability of a material to absorb energy and plastically deform without fracturing. Material toughness is defined as the amount of energy per volume that a material can absorb before rupturing. It is also defined as the resistance to fracture of a material when stressed.

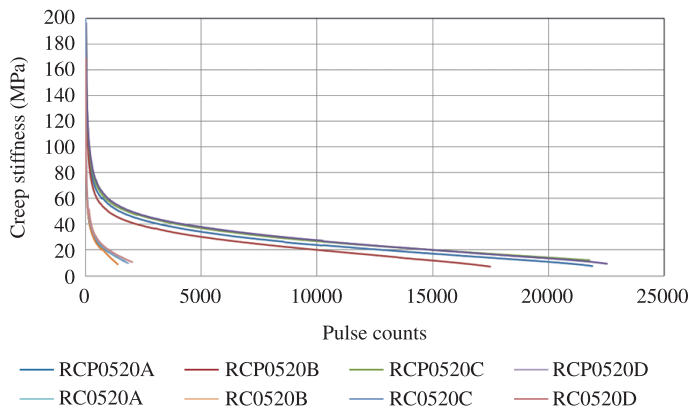

Figure 9. Creep stiffness vs. pulse count of specimens with a loading pattern of $500 \mathrm{~ms}$ load $-2000 \mathrm{~ms}$ rest period (100 mm diameter gyratory compactor specimens). 


\subsection{Comparison of repeated load creep testing results of $100 \mathrm{~mm}$ gyratory compactor specimens with Marshall specimens}

In this part of the study, relevant figures are given in order to emphasize the very positive simulation effort of gyratory compaction when compared to standard Marshall compaction. At this point the physical properties and loading conditions of reference and M-03 type polypropylene fiber modified Marshall specimens are given in Table 8 .

The physical similarities of the gyratory and Marshall compacted specimens can be visualised through Tables 7 and 8. Although these specimens, at the first glance, look very similar to each other from their physical properties, in fact, as will be presented in the further parts of the study, the rheological behaviour of gyratory compactor specimens is much more preferable when compared to Marshall specimens. The statistical analysis of these specimens has been carried out by Hotelling's T-squared test. Hotelling's T-squared distribution is important because it arises as the distribution of a set of statistics which are natural generalisations of the statistics underlying Student's t distribution. In particular, the distribution arises in multivariate statistics in undertaking tests of the differences between the (multivariate) means of different populations, where tests for univariate problems would make use of a t-test. It is proportional to the F distribution ${ }^{75}$.

Our hypothesis $\left(H_{0}\right)$, was arising from the nature of the Superpave gyratory compaction, though the specimens prepared by gyratory and Marshall compaction might seem as if they are very similar to each other from the physical properties point of view. In fact, they are completely different compaction techniques and gyratory compaction is modelling the real in-situ compaction in a much better manner. In Tables 9 and 10, respectively, the reader might find the Hotelling $\mathrm{T}^{2}$ test results for $95 \%$ confidence interval for:

a) Reference specimens;

b) Polypropylene fiber modified specimens.

Table 8. Physical properties and loading conditions of reference and M-03 type polypropylene fiber-modified Marshall specimens ${ }^{29}$.

\begin{tabular}{|c|c|c|c|c|c|}
\hline $\begin{array}{c}\text { Specimen } \\
\text { number }\end{array}$ & $\begin{array}{c}\text { Height } \\
(\mathrm{mm})\end{array}$ & $\begin{array}{c}\text { V.M.A } \\
(\%)\end{array}$ & $\begin{array}{c}\text { Vf } \\
(\%)\end{array}$ & $\begin{array}{c}\text { Air Voids } \\
(\%)\end{array}$ & $\begin{array}{c}\text { Unit weight } \\
\left(\mathbf{k g} \cdot \mathbf{m}^{-3}\right)\end{array}$ \\
\hline $\mathrm{RC} 0505 \mathrm{~A}$ & 58.00 & 14.968 & 76.102 & 3.218 & 2462 \\
\hline $\mathrm{RC} 0505 \mathrm{~B}$ & 58.00 & 15.015 & 75.824 & 3.271 & 2460 \\
\hline $\mathrm{RC} 0505 \mathrm{C}$ & 58.00 & 14.976 & 76.055 & 3.227 & 2461 \\
\hline RC0505D & 58.00 & 15.185 & 74.826 & 3.465 & 2455 \\
\hline RC0510A & 58.00 & 14.896 & 76.535 & 3.136 & 2464 \\
\hline RC0510B & 59.00 & 15.315 & 74.079 & 3.612 & 2452 \\
\hline $\mathrm{RC} 0510 \mathrm{C}$ & 58.00 & 14.925 & 76.362 & 3.169 & 2463 \\
\hline RC0510D & 58.00 & 15.003 & 75.898 & 3.257 & 2461 \\
\hline $\mathrm{RC} 0515 \mathrm{~A}$ & 59.00 & 14.855 & 76.786 & 3.089 & 2465 \\
\hline RC0515B & 59.00 & 15.104 & 75.300 & 3.372 & 2458 \\
\hline $\mathrm{RC} 0515 \mathrm{C}$ & 58.00 & 14.955 & 76.181 & 3.203 & 2462 \\
\hline RC0515D & 58.00 & 14.869 & 76.702 & 3.105 & 2464 \\
\hline $\mathrm{RC} 0520 \mathrm{~A}$ & 58.00 & 14.692 & 77.785 & 2.904 & 2470 \\
\hline RC0520B & 58.00 & 15.021 & 75.788 & 3.278 & 2460 \\
\hline $\mathrm{RC} 0520 \mathrm{C}$ & 59.00 & 14.829 & 76.942 & 3.060 & 2466 \\
\hline RC0520D & 58.00 & 15.080 & 75.440 & 3.345 & 2458 \\
\hline RCP0505A & 59.00 & 16.080 & 69.914 & 4.484 & 2428 \\
\hline RCP0505B & 60.00 & 16.410 & 68.239 & 4.859 & 2419 \\
\hline RCP0505C & 60.00 & 16.332 & 68.627 & 4.771 & 2421 \\
\hline RCP0505D & 58.00 & 15.738 & 71.727 & 4.094 & 2438 \\
\hline RCP0510A & 58.00 & 15.896 & 69.914 & 4.112 & 2437 \\
\hline RCP0510B & 59.00 & 16.015 & 68.239 & 4.375 & 2432 \\
\hline RCP0510C & 60.00 & 16.227 & 68.627 & 4.528 & 2428 \\
\hline RCP0510D & 60.00 & 16.358 & 69.672 & 4.799 & 2421 \\
\hline $\mathrm{RCP} 0515 \mathrm{~A}$ & 59.00 & 15.982 & 70.427 & 4.372 & 2432 \\
\hline RCP0515B & 60.00 & 16.410 & 68.239 & 4.859 & 2420 \\
\hline RCP0515C & 60.00 & 16.332 & 68.627 & 4.771 & 2422 \\
\hline RCP0515D & 59.00 & 15.827 & 71.249 & 4.195 & 2437 \\
\hline RCP0520A & 59.00 & 15.853 & 69.914 & 4.254 & 2434 \\
\hline RCP0520B & 59.00 & 15.727 & 68.239 & 4.126 & 2440 \\
\hline RCP0520C & 60.00 & 16.377 & 68.627 & 4.659 & 2424 \\
\hline RCP0520D & 60.00 & 16.196 & 69.964 & 4.451 & 2428 \\
\hline
\end{tabular}


Table 9. Sample mean difference vector of the specimens prepared by utilising Superpave gyratory compaction and Marshall compaction and variance-covariance matrix (for reference specimens).

$\bar{d}$

\begin{tabular}{|c|c|c|c|c|c|}
\hline \multicolumn{3}{|c|}{ Height (mm) } & \multicolumn{3}{|c|}{3.213750} \\
\hline \multicolumn{3}{|c|}{ V.M.A (\%) } & \multicolumn{3}{|c|}{-0.524375} \\
\hline \multicolumn{3}{|c|}{ Vf $(\%)$} & \multicolumn{3}{|c|}{2.810625} \\
\hline \multicolumn{3}{|c|}{ Air Voids (\%) } & \multicolumn{3}{|c|}{-0.183750} \\
\hline \multicolumn{3}{|c|}{ Unit weight $\left(\mathrm{kg} \cdot \mathrm{m}^{-3}\right)$} & \multicolumn{3}{|c|}{-1.016875} \\
\hline \multicolumn{6}{|c|}{$\mathbf{S}_{\mathrm{d}}$} \\
\hline & $\begin{array}{c}\text { Height } \\
(\mathbf{m m})\end{array}$ & $\begin{array}{l}\text { V.M.A } \\
(\%)\end{array}$ & $\begin{array}{l}\text { Vf } \\
(\%)\end{array}$ & $\begin{array}{c}\text { Air Voids } \\
(\%)\end{array}$ & $\begin{array}{l}\text { Unit weight } \\
\left(\mathrm{kg}^{\left.-\mathrm{m}^{-3}\right)}\right.\end{array}$ \\
\hline Height (mm) & 0.20110500 & 0.02420417 & -0.1421892 & 0.02700167 & -0.6907725 \\
\hline V.M.A (\%) & 0.02420417 & 0.09541292 & -0.5892571 & 0.10799583 & -2.7361454 \\
\hline $\mathrm{Vf}(\%)$ & -0.14218917 & -0.58925708 & 3.6409263 & -0.66699750 & 16.8981513 \\
\hline Air Voids (\%) & 0.02700167 & 0.10799583 & -0.6669975 & 0.12225167 & -3.0971942 \\
\hline Unit weight $\left(\mathrm{kg} \cdot \mathrm{m}^{-3}\right)$ & -0.69077250 & -2.73614542 & 16.8981513 & -3.09719417 & 78.4684896 \\
\hline
\end{tabular}

$T^{2}=1652369 F=\frac{n-p}{(n-1) \cdot p} T^{2} F=\frac{16-5}{(16-1) \cdot 5} 1652369=242402.5323 \cdot>F_{5,11,0.05}=3.20 H_{0}$ hypothesis is rejected

Table 10. Sample mean difference vector of the specimens prepared by utilising Superpave gyratory compaction and Marshall compaction and variance-covariance matrix (for polypropylene fiber modified specimens).

\begin{tabular}{|c|c|c|c|c|c|}
\hline \multicolumn{6}{|c|}{$\bar{d}$} \\
\hline & Height (mm) & & & 3.22187500 & \\
\hline & V.M.A (\%) & & & -0.09277957 & \\
\hline & Vf $(\%)$ & & & 1.15018396 & \\
\hline & Air Voids (\%) & & & 0.22484121 & \\
\hline & Unit weight $\left(\mathrm{kg} \cdot \mathrm{m}^{-3}\right)$ & & & -13.41110778 & \\
\hline \multicolumn{6}{|c|}{$\mathbf{S}_{\mathrm{d}}$} \\
\hline & Height (mm) & V.M.A (\%) & $\operatorname{Vf}(\%)$ & Air Voids (\%) & Unit weight $\left(\mathrm{kg} \cdot \mathrm{m}^{-3}\right)$ \\
\hline Height (mm) & 0.5240429 & 0.17733313 & -0.6002367 & 0.19697577 & -4.942531 \\
\hline V.M.A (\%) & 0.1773331 & 0.07090027 & -0.2207519 & 0.07701240 & -1.966763 \\
\hline Vf $(\%)$ & -0.6002367 & -0.22075192 & 1.6311587 & -0.24940876 & 5.874158 \\
\hline Air Voids (\%) & 0.1969758 & 0.07701240 & -0.2494088 & 0.08867743 & -2.234176 \\
\hline Unit weight $\left(\mathrm{kg} \cdot \mathrm{m}^{-3}\right)$ & -4.9425314 & -1.96676297 & 5.8741576 & -2.23417579 & 56.990507 \\
\hline
\end{tabular}

$T^{2}=8882.903 F=\frac{n-p}{(n-1) \cdot p} T^{2} F=\frac{16-5}{(16-1) \cdot 5} 8882.903=1302.82577 \cdot>F_{5,11,0.05}=3.20 H_{0}$ hypothesis is rejected

The reader can easily see that for both reference and polypropylene modified specimen sets, hypothesis $\left(H_{0}\right)$ are rejected. Therefore it can be clearly said that the two compaction methods are completely different in their nature, though one may produce specimens in such a manner that their physical properties can be very similar to each other at the first glance. This can be clearly seen with the repeated creep test results.

With these gyratory compactor specimens, the same repeated creep testing scheme is once more utilised which is being explored in a detailed manner by the study of the lead author ${ }^{27,31}$. Below, the comparative graphs both for strain accumulation and creep stiffness is being proposed between Figures 10 to 25 respectively.
When these figures are explored in a detailed manner, it can be clearly visualised that, gyratory compactor has a definite superiority over Marshall compaction in terms of the time of the asphalt specimens to reach their end of service lives. Below, first of all, the rheological behaviour of reference specimens will be explored in a detailed manner. Then these analyses will be carried out for polypropylene fiber modified specimens.

5.4.1. Further analysis of the rheological behaviour of reference specimens

The mechanical behaviour of asphalt specimens prepared by gyratory $(\mathrm{G})$ and Marshall $(\mathrm{M})$ compaction exhibits a very similar behaviour when the reference and 
polypropylene modified specimens are concerned groupwise except RC0505A (M), RC0505C (M), RC0505B (G) and RC0505A (G). The explanation of this basically depends on the physical property differences with respect to other specimens which can be visualised in Tables 7 and 8 . The same argument above which was stated for the accumulated strain is also valid for the creep stiffness analyses (it has to be mentioned that, for specimen RC0505B (G), the test has continued until the "total" failure of the specimen unintentionally so the "different" rheological behaviour of the specimen is mainly because of this fact).

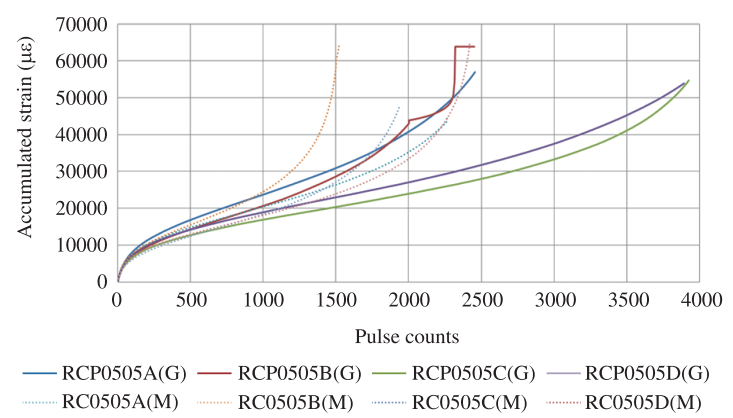

Figure 10. Comparison of gyratory compactor specimens with Marshall specimens via accumulated strain vs. pulse count basis with a loading pattern of $500 \mathrm{~ms}$ load $-500 \mathrm{~ms}$ rest period (REFERENCE).

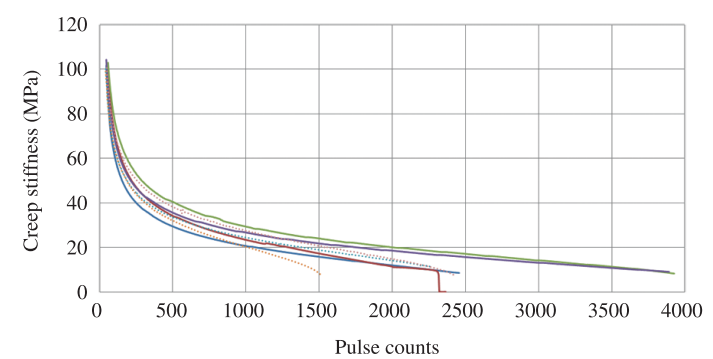

$-\mathrm{RCP} 0505 \mathrm{~A}(\mathrm{G})-\mathrm{RCP} 0505 \mathrm{~B}(\mathrm{G})-\mathrm{RCP} 0505 \mathrm{C}(\mathrm{G})-\mathrm{RCP} 0505 \mathrm{D}(\mathrm{G})$

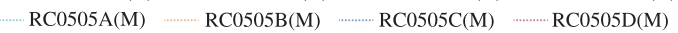

Figure 11. Comparison of gyratory compactor specimens with Marshall specimens via creep stiffness vs. pulse count basis with a loading pattern of $500 \mathrm{~ms}$ load $-500 \mathrm{~ms}$ rest period (REFERENCE).

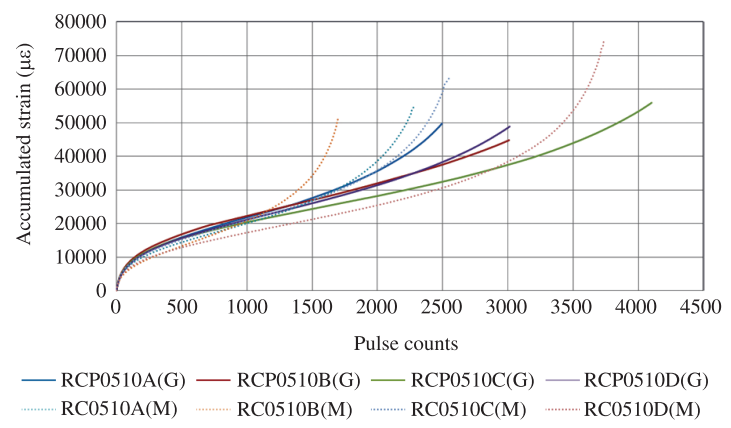

Figure 12. Comparison of gyratory compactor specimens with Marshall specimens via accumulated strain vs. pulse count basis with a loading pattern of $500 \mathrm{~ms}$ load - $1000 \mathrm{~ms}$ rest period (REFERENCE).
The mechanical behavior of asphalt specimens prepared by gyratory and Marshall compaction exhibits a very similar behaviour when the reference and polypropylene modified specimens are concerned groupwise except RC0510D (M) and RC0510C (G). The explanation of this basically depends on the physical property differences with respect to other specimens which can be visualised in Tables 7 and 8 . The same argument above which was stated for the accumulated strain is also valid for the creep stiffness analyses.

The mechanical behavior of asphalt specimens prepared by gyratory and Marshall compaction exhibits a very similar

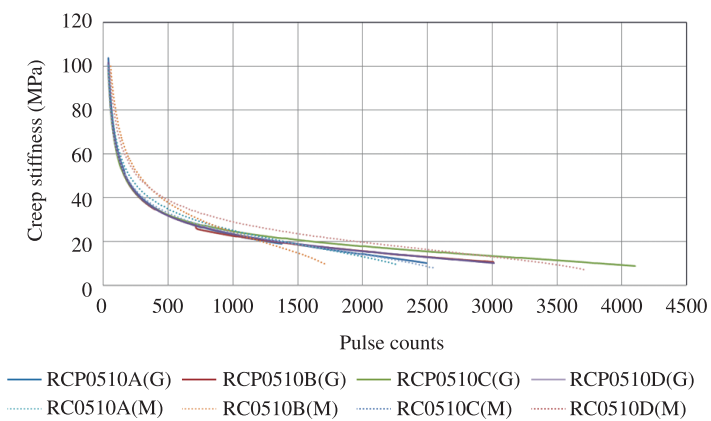

Figure 13. Comparison of gyratory compactor specimens with Marshall specimens via creep stiffness vs. pulse count basis with a loading pattern of $500 \mathrm{~ms}$ load $-1000 \mathrm{~ms}$ rest period (REFERENCE).

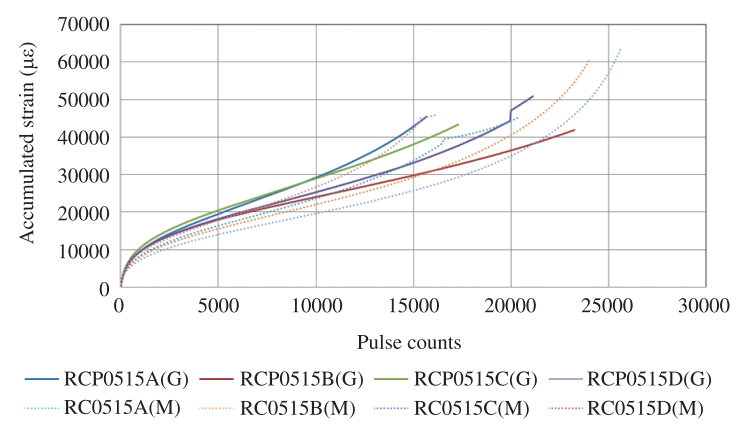

Figure 14. Comparison of gyratory compactor specimens with Marshall specimens via accumulated strain vs. pulse count basis with a loading pattern of $500 \mathrm{~ms}$ load - $1500 \mathrm{~ms}$ rest period (REFERENCE).

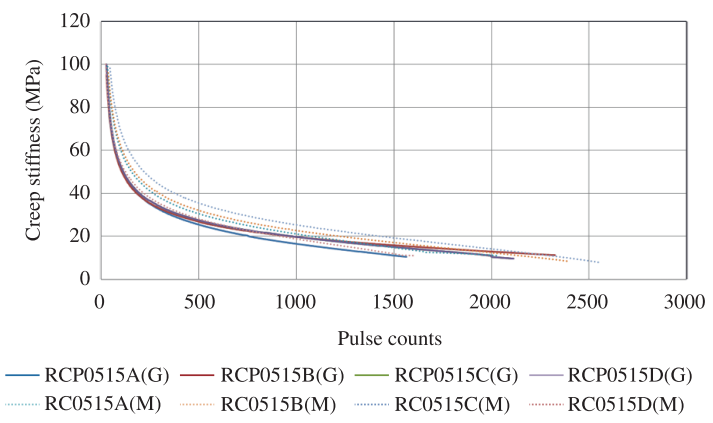

Figure 15. Comparison of gyratory compactor specimens with Marshall specimens via creep stiffness vs. pulse count basis with a loading pattern of $500 \mathrm{~ms}$ load $-1500 \mathrm{~ms}$ rest period (REFERENCE). 
behaviour when the reference and polypropylene modified specimens are concerned groupwise except RC0515B (M) and RC0510C (M). The explanation of this basically depends on the physical property differences with respect to other specimens which can be visualised in Tables 7 and 8 . The same argument above which was stated for the accumulated strain is also valid for the creep stiffness analyses. Furthermore, the "different" rheological behavior of specimen RC0515D (G) can be explained by the phenomenon that the data acquisition system of UTM-5P works in a way that, at the point where the screen of the software is replaced with the spreadsheet software for the check of whether the $\log$ of the strains and stiffness are correctly taken or not, the logs are taken in a wrong manner and the graphs have a sort of "discontinuity" at the anticipated points.

The same argument is valid for the mechanical behavior of asphalt specimens prepared by gyratory and Marshall compaction (RC0520A (M) and RC0520B (G)). The same argument above which was stated for the accumulated strain is also valid for the creep stiffness analyses. Furthermore, the "different" rheological behavior of specimen RC0520D (G) in Figure 17 can be explained by the phenomenon that the data acquisition system of UTM-5P works in a way that, at the point where the screen of the software is replaced with the spreadsheet software for the check of whether the log of the strains and stiffness are correctly taken or not, the logs are taken in a wrong manner and the graphs have a sort of "discontinuity" at the anticipated points.

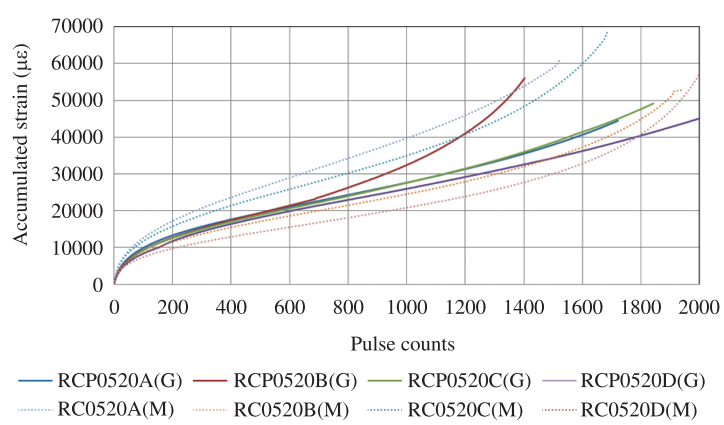

Figure 16. Comparison of gyratory compactor specimens with Marshall specimens via accumulated strain vs. pulse count basis with a loading pattern of $500 \mathrm{~ms}$ load $-2000 \mathrm{~ms}$ rest period (REFERENCE).

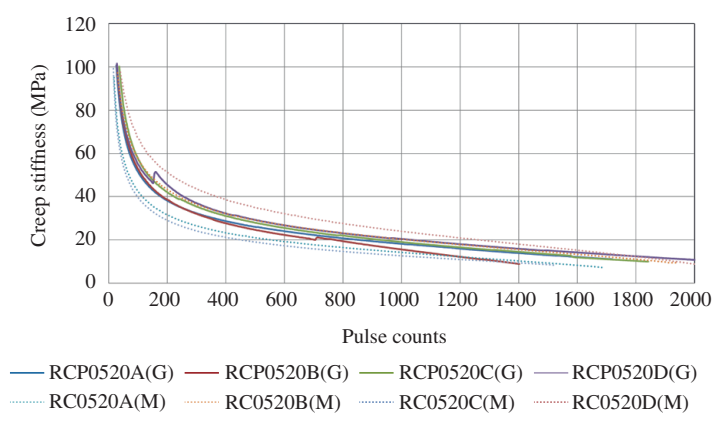

Figure 17. Comparison of gyratory compactor specimens with Marshall specimens via creep stiffness vs. pulse count basis with a loading pattern of $500 \mathrm{~ms}$ load $-2000 \mathrm{~ms}$ rest period (REFERENCE).
When $500 \mathrm{~ms}$ load - $500 \mathrm{~ms}$ rest, $500 \mathrm{~ms}$ load - $1000 \mathrm{~ms}$ rest, $500 \mathrm{~ms}$ load $-1500 \mathrm{~ms}$ rest and $500 \mathrm{~ms}$ load $-2000 \mathrm{~ms}$ rest loading patterns at $50{ }^{\circ} \mathrm{C}$ temperature and $500 \mathrm{kPa}$ stress level on strain accumulation basis are analysed respectively, it can be seen that the time of the reference specimens to reach their end of service lives that have been prepared via gyratory compaction are 1.56 times, 1.23 times, 0.90 times and 0.98 times longer than the specimens prepared with Marshall compaction (please refer to Figures 10, 12, 14 and 16 respectively). To give a more representative figure it can be said that gyratory compaction enhances the reference mixtures' end of service life performances approximately $20 \%$

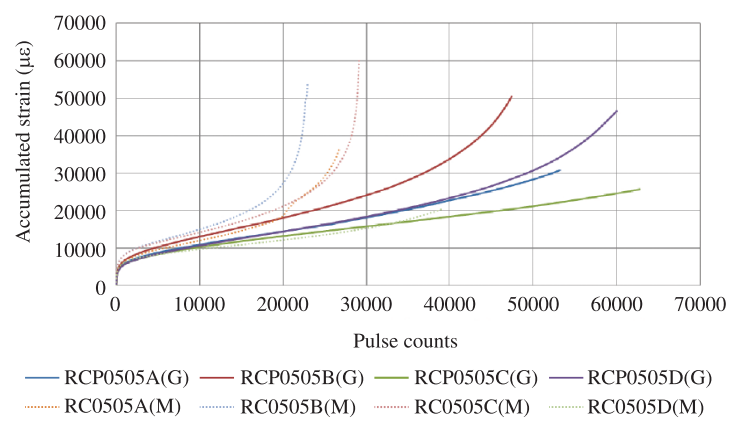

Figure 18. Comparison of gyratory compactor specimens with Marshall specimens via accumulated strain vs. pulse count basis with a loading pattern of $500 \mathrm{~ms}$ load $-500 \mathrm{~ms}$ rest period (POLYPROPYLENE MODIFIED).

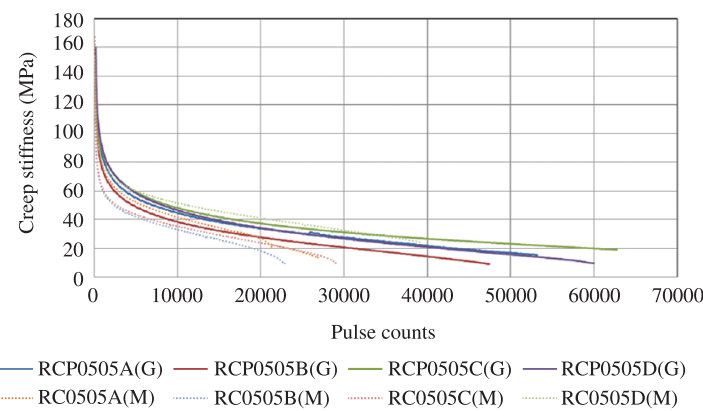

Figure 19. Comparison of gyratory compactor specimens with Marshall specimens via creep stiffness vs. pulse count basis with a loading pattern of $500 \mathrm{~ms}$ load $-500 \mathrm{~ms}$ rest period (POLYPROPYLENE MODIFIED).

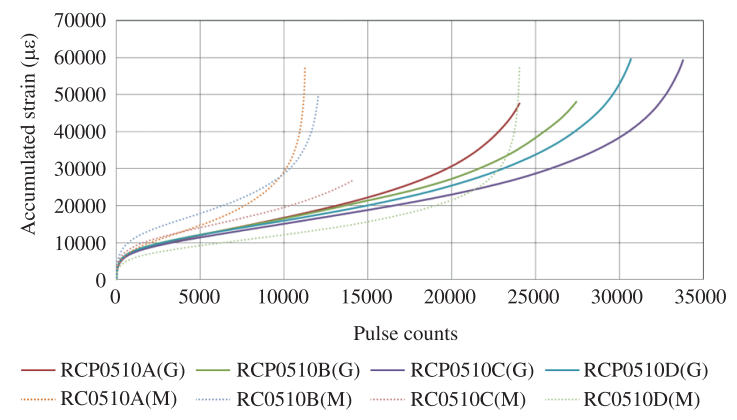

Figure 20. Comparison of gyratory compactor specimens with Marshall specimens via accumulated strain vs. pulse count basis with a loading pattern of $500 \mathrm{~ms}$ load - $1000 \mathrm{~ms}$ rest period (POLYPROPYLENE MODIFIED). 
when four of the different loading patterns are analysed in an arithmetical basis. In pavement engineering, it is not possible to give an "exact value" to lots of the measured variables but one can easily notice from the above mentioned four graphs that gyratory compactor specimens considerably shift the whole system to right side (via pulse counts axis) which shows us the added value of the gyratory compaction technique.

One can easily visualise the very same added value of the gyratory compaction technique to the failure point via Figures 11, 13, 15 and 17 respectively from the creep stiffness verses pulse count graphs. Creep stiffness values

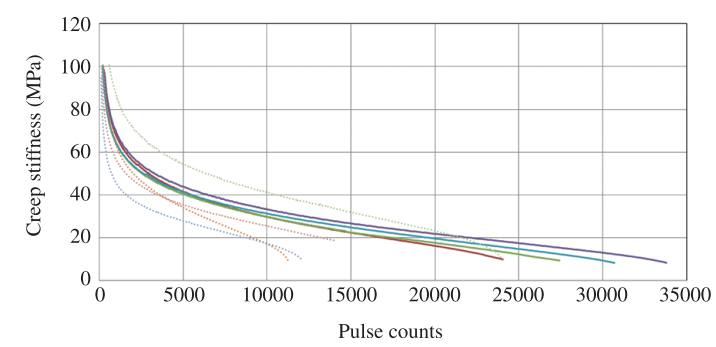

- RCP0510A(G) - RCP0510B(G) - RCP0510C(G) - RCP0510D(G)

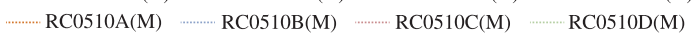

Figure 21. Comparison of gyratory compactor specimens with Marshall specimens via creep stiffness vs. pulse count basis with a loading pattern of $500 \mathrm{~ms}$ load - $1000 \mathrm{~ms}$ rest period (POLYPROPYLENE MODIFIED).

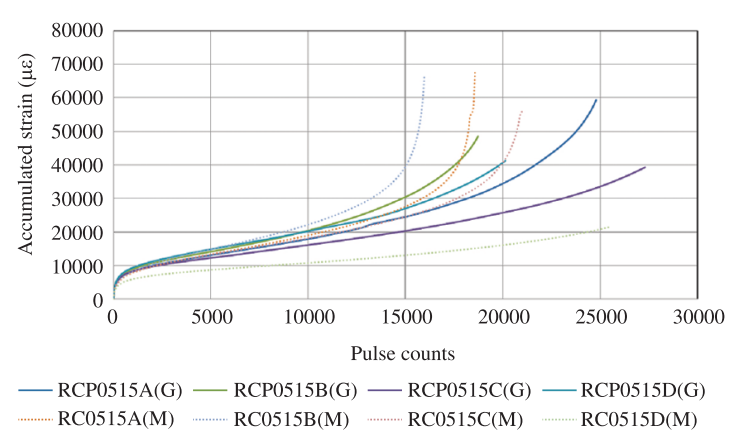

Figure 22. Comparison of gyratory compactor specimens with Marshall specimens via accumulated strain vs. pulse count basis with a loading pattern of $500 \mathrm{~ms}$ load $-1500 \mathrm{~ms}$ rest period (POLYPROPYLENE MODIFIED).

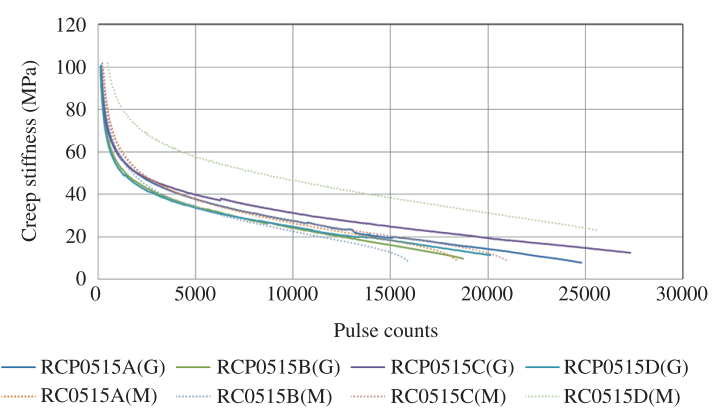

Figure 23. Comparison of gyratory compactor specimens with Marshall specimens via creep stiffness vs. pulse count basis with a loading pattern of $500 \mathrm{~ms}$ load - $1500 \mathrm{~ms}$ rest period (POLYPROPYLENE MODIFIED). drop to a certain level through the tests which are $10 \mathrm{MPa}$. This level can be accepted as the termination of the test. For both specimen types, the termination stiffness values are the same, but the pattern of the decrease in these values shows very different behaviours. When the specimens prepared with Marshall compactor fail, the creep stiffness of the specimens prepared via gyratory compaction have only dropped to their $30 \%$ of original values. This is a very significant improvement from pavement engineering point of view.

\subsubsection{Further analysis of the rheological behaviour of polypropylene fiber modified specimens}

The mechanical behavior of asphalt specimens prepared by gyratory and Marshall compaction exhibits a very similar behaviour when the reference and polypropylene modified specimens are concerned groupwise except RCP0505A (M), RCP0505B (M), RCP0505A (G) and RCP0505C (G). These specimens had shown a different rheological behavior than other specimens as the other two group specimens had entered tertiary creep region, these two specimens were in secondary creep region. The explanation of this basically depends on the physical property differences between these specimens which can be visualised in Tables 7 and 8 . Because of this reason, the test had been interrupted earlier. For the calculation of the life of the specimens under creep test, for all of the specimens, reaching a creep stiffness value of less than $10 \mathrm{MPa}$ was accepted for the termination of the

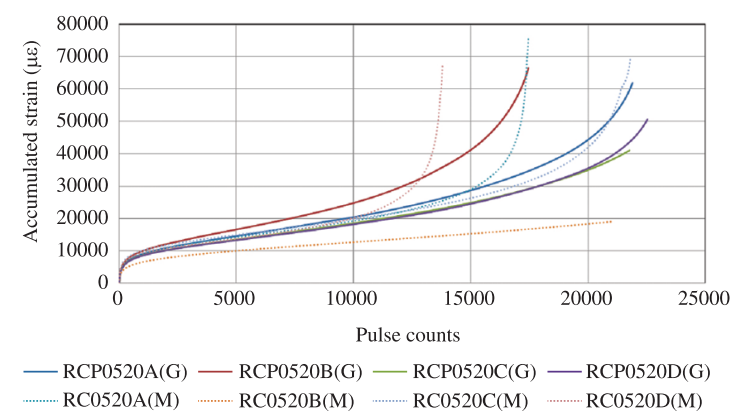

Figure 24. Comparison of gyratory compactor specimens with Marshall specimens via accumulated strain vs. pulse count basis with a loading pattern of $500 \mathrm{~ms}$ load - $2000 \mathrm{~ms}$ rest period (POLYPROPYLENE MODIFIED).

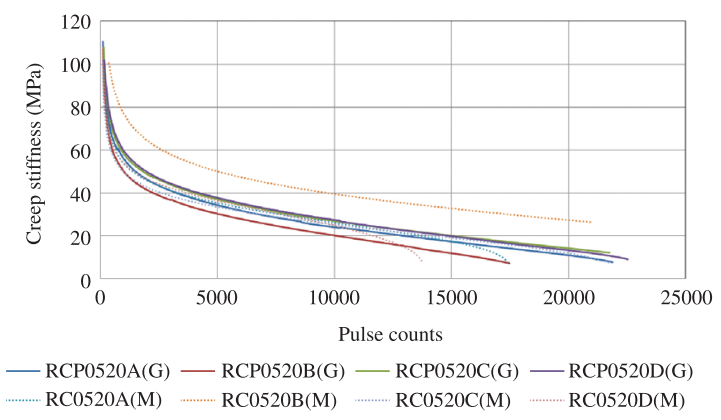

Figure 25. Comparison of gyratory compactor specimens with Marshall specimens via creep stiffness vs. pulse count basis with a loading pattern of $500 \mathrm{~ms}$ load - $2000 \mathrm{~ms}$ rest period (POLYPROPYLENE MODIFIED). 
repeated creep tests. The same argument above which was stated for the accumulated strain is also valid for the creep stiffness analyses.

Similar arguments are valid as the above discussions for Figures 20 and 21. Specially, while testing RCP0510C (M) specimen, a problem in the UTM-5P occurred and the test was interrupted around 14000 pulses (which is also 5 hours and 50 minutes of testing).

In Figure 22, RCP0515D (M) needs attention. RCP0515D (M) has a different rheological behaviour than the others in such a way that the other three group specimens has entered tertiary creep region, this specimen has been in secondary creep region. The explanation of this basically depends on the physical property differences between these specimens which can be visualised in Table 8 . But the testing time for this specimen corresponds to 13 hours 54 minutes therefore the strain accumulation and creep stiffness of this specimen is being presented in the graphs.

This time, the rheological behaviour of RCP0520B (M) is different than other specimens. But as the testing time of this specimen corresponds to 14 hours 35 minutes, the curves for this specimen are given.

In all of the strain accumulation and creep stiffness graphs, there are some specimens which do not follow the rheological behaviour of their accompanying ones but due to the viscoelastic, elastoplastic, thermoplastic and viscoplastic nature of asphalt, under a high ambient temperature of $50{ }^{\circ} \mathrm{C}$ and a stress level of $500 \mathrm{kPa}$ (which presents a very destructive level of loading), these minute differences can be acceptable.

When $500 \mathrm{~ms}$ load $-500 \mathrm{~ms}$ rest, $500 \mathrm{~ms}$ load $-1000 \mathrm{~ms}$ rest, $500 \mathrm{~ms}$ load $-1500 \mathrm{~ms}$ rest and $500 \mathrm{~ms}$ load $-2000 \mathrm{~ms}$ rest loading patterns at $50{ }^{\circ} \mathrm{C}$ temperature and $500 \mathrm{kPa}$ stress level are analysed respectively, it can be seen that the time of the M-03 type polypropylene fiber reinforced specimens to reach their end of service lives that have been prepared via gyratory compaction are 1.80 times, 1.72 times, 1.01 times and 1.13 times longer than the specimens prepared with Marshall compaction (please refer to Figures 18, 20, 22 and 24 respectively). To give a more representative figure it can be said that gyratory compaction enhances the polypropylene modified mixtures' end of service life performances approximately $42 \%$. Also it can be concluded that gyratory compaction is more favourable to enhance the mechanical performance of the asphalt specimens by carrying out polypropylene fiber modification. The readers should bear in their minds that, due to the very long nature of repeated creep testing technique of the leading author, many of the experiments have been cut off at earlier periods than the real failure of the polypropylene modified specimens. According to the further analyses that have been carried out, it can be definitely said that the polypropylene modified

\section{References}

1. Hofstra A and Klomp AJG. Permanent Deformation of Flexible Pavements under Simulated Road Traffic Conditions. In: Proceedings of the Third International Conference on the Structural Design of Asphalt Pavements; 1972; London, England. Ann Arbor: University of Michigan; 1972. v. 1. mixtures' end of service life performances approximately $55 \%$ longer. This is a dramatic development when concerned from pavement engineering point of view.

\section{Conclusions and Recommendations}

From the above discussions, it can be clearly be concluded that the lives of the polypropylene fiber modified asphalt specimens under repeated creep loading at different loading patterns increased by 8-18 times versus reference specimens when gyratory compaction is being utilised in the preparation of $100 \mathrm{~mm}$ diameter asphalt specimens (when four different loading patterns were utilised in the testing protocols). This increase was only 5-12 times in the asphalt specimens prepared via utilising Marshall compaction technique. This is a very significant improvement from pavement engineering point of view. When two different techniques are compared, to give a more representative figure, it can be said that gyratory compaction enhances the reference mixtures' end of service life performances approximately " $20 \%$ ". This increase gets up to " $55 \%$ " for polypropylene modification. The results from both of the analysis of the tested specimens show that the addition of polypropylene fibers improves the behaviour of the specimens in a very pronounced manner by increasing the life of samples under repeated creep testing. Besides, it is clear that gyratory compaction introduces a much realistic compaction simulation effort in the laboratory environment especially for polypropylene modified asphalt when viewed from the large experimental database obtained all throughout the years. At this point, from all of the above discussions, it can be clearly said that design gyration number should be 40 for reference and 33 for polypropylene modified specimens under medium traffic conditions for the similar and specific type of aggregate sources, bitumen, aggregate gradation, mix proportioning, modification technique and laboratory conditions. For further research, more insight to the optimal design gyration number for $100 \mathrm{~mm}$ specimens obtained via gyratory specimens for reference and polypropylene fiber modified specimens should be sought. Also, static creep tests should also be undertaken in order to get a better insight to the problem. Moreover, the laboratory findings can be verified from the repeated creep analysis of cores taken from site. Furthermore, the major drawbacks of the Marshall compaction should be solved by proposing a newer testing regime and interpretation of these test results.

\section{Acknowledgements}

This study was supported by Anadolu University Research Fund with Grant no: 08.02.38.
2. Uge P and Van de Loo PJ. Permanent Deformation of Asphalt Mixes. Canadian Technical Asphalt Association. 1974; 19:307-341.

3. Van de Loo PJ. Creep testing, A Simple Tool to Judge Asphalt Mix Stability. In: Proceedings of the Annual Meeting of the Association of Asphalt Paving Technologists; 1974; Williamsburg, Virgínia. Williamsburg; 1974. v. 43. 
4. Hills JF, Brien D and Van de Loo PJ. The Correlation of Rutting and Creep Tests on Asphalt Mixes. Journal of the Institute of Petroleum. 1974. Paper IP 74-001.

5. De Hilster E and Van de Loo PJ. Influence of Test Parameters. Amsterdam: Koninklijke/Shell-Laboratories; 1977.

6. Van de Loo PJ and De Hilster E. Creep Data of Samples Cored from Pavements. London: Shell International Petroleum Company Limited; 1978.

7. Bolk HJNA and Van de Loo PJ. The Creep Test: A Routine Method for the Design of Stable Asphalt Mixes. Amsterdam: Koninklijke/Shell-Laboratories; 1979.

8. Brown ER, Kandhal PS and Zhang J. Performance testing for hot mix asphalt. NCAT Report 01-05. Auburn: National Center for Asphalt Technology; 2001.

9. Brule B. Polymer-modified asphalt cements used in the road construction industry: basic principles. Transport Research Record. 1996; 1535:48-53. http://dx.doi.org/10.3141/1535-07

10. Brown SF, Rowlett RD and Boucher JL. Asphalt modification. In: Proceedings of the Conference on US SHRP Highway Research Program: Sharing the Benefits; 1990. ICE; 1990. p. 181-203.

11. Collins JH, Bouldin MG, Gelles R and Berker A. Improved performance of paving asphalts by polymer modification. Journal of the Association of Asphalt Paving Technologists. 1991; 60:43-79.

12. Goodrich JL. Asphaltic binder rheology, asphalt concrete rheology and asphalt concrete mix properties. Journal of the Association of Asphalt Paving Technologists. 1991; 60:80-120.

13. Isacsson $\mathrm{U}$ and $\mathrm{Lu} \mathrm{X}$. Testing and appraisal of polymer modified road bitumens - state of the art. Materiaux et constructions. 1995; 28(177):139-159.

14. Hills JF. The Creep of Asphalt Concrete Mixes. Journal of the Institute of Petroleum. 1973; 59(570):247

15. Van de Loo PJ. Practical approach to the prediction of rutting in asphalt pavements: the Shell Method". Transportation Research Record: Journal of the Transportation Research Board. 1976; 616:15-21.

16. Recommendation for the Performance of Unconfined Static Creep Test in Asphalt Specimens. In: Proceedings of the International Symposium on Plastic Deformability of Bituminous Mixes; 1977; Zurich. Zurich, 1977. p. 335-359.

17. Roberts FL, Kandhal PS, Brown ER, Lee D-Y and Kennedy TW. Hot Mix Asphalt Materials, Mixture Design and Construction. 2nd ed. Lanhamn: NAPA Education Foundation; 1996.

18. Tapkın S and Özcan Ş. Determination of the Optimal Polypropylene Fiber Addition to the Dense Bituminous Mixtures by the Aid of Mechanical and Optical Means. The Baltic Journal of Road and Bridge Engineering. 2012; 7(1):22-29. http://dx.doi.org/10.3846/bjrbe.2012.03

19. McGennis RB, Anderson RM, Perdomo D and Turner P. Issues Pertaining to Use of Superpave Gyratory Compactor. Transportation Research Record. 1996; 1543:139-144. http:// dx.doi.org/10.3141/1543-18

20. Brown ER and Haddock JE. Method To Ensure Stone-on-Stone Contact in Stone Matrix Asphalt Paving Mixtures. Transportation Research Record. 1997; 1583:11-18. http:// dx.doi.org/10.3141/1583-02

21. Birgisson B, Sholar G and Roque R. Evaluation of a Predicted Dynamic Modulus for Florida Mixtures. Transportation Research Record. 2005; 1929:200-207.
22. Faheem AF, Bahia HU and Ajideh H. Estimating Results of a Proposed Simple Performance Test for Hot-Mix Asphalt from Superpave Gyratory Compactor Results. Transportation Research Record. 2005; 1929:104-113.

23. Alvarez AE, Martin AE and Estakhri C. Internal structure of compacted permeable friction course mixtures. Construction and Building Materials. 2010; 24(6):1027-1035. http://dx.doi. org/10.1016/j.conbuildmat.2009.11.015

24. Doh YS, Yun KK, Amirkhanian SJ and Kim KW. Framework for developing a static strength test for measuring deformation resistance of asphalt concrete mixtures. Construction and Building Materials. 2007; 21(12):2047-2058. http://dx.doi. org/10.1016/j.conbuildmat.2006.06.032

25. Anochie-Boateng J and Maina J. Permanent deformation testing for a new South African mechanistic pavement design method. Construction and Building Materials. 2012; 26(1):541-546. http://dx.doi.org/10.1016/j.conbuildmat.2011.06.055

26. Liu Q, García A, Schlangen E and van de Ven M. Induction healing of asphalt mastic and porous asphalt concrete. Construction and Building Materials. 2011; 25(9):3746-3752. http://dx.doi.org/10.1016/j.conbuildmat.2011.04.016

27. Tapkın S, Çevik A and Uşar Ü. Accumulated Strain Prediction of Polypropylene Modified Marshall Specimens in Repeated Creep Test Using Artificial Neural Networks. Expert Systems With Applications. 2009A; 36(8):11186-11197. http://dx.doi. org/10.1016/j.eswa.2009.02.089

28. Tapkin S. The effect of polypropylene fibers on asphalt performance. Building and Environment. 2008; 43(6):10651071. http://dx.doi.org/10.1016/j.buildenv.2007.02.011

29. Tapkın S, Uşar Ü, Tuncan A and Tuncan M. Repeated Creep Behavior of Polypropylene Fiber-Reinforced Bituminous Mixtures. Journal of Transportation Engineering, ASCE. 2009B; 135(4):240-249. http://dx.doi.org/10.1061/ (ASCE)0733-947X(2009)135:4(240)

30. Tapkın S, Çevik A and Uşar Ü. Prediction of Marshall test results for polypropylene modified dense bituminous mixtures using neural networks. Expert Systems with Applications. 2010; 37(6):4660-4670. http://dx.doi. org/10.1016/j.eswa.2009.12.042

31. Tapkın S, Uşar Ü, Özcan Ö and Çevik A. Polypropylene fiber-reinforced bitumen. In: McNally T, editor. Polymer modified bitumen: Properties and characterisation. Woodhead Publishing; 2011. p. 136-194. ISBN: 0857090488.

32. Uşar Ü. Investigation of rheological behaviours of dense bituminous mixtures with polypropylene fiber in repeated creep test. [Thesis]. Eskişehir, Turkey: Anadolu University; 2007. (in Turkish).

33. Lee SJ, Rust JP, Hamouda H, Kim YR and Borden RH. Fatigue Cracking Resistance of Fiber-Reinforced Asphalt Concrete. Textile Research Journal. 2005; 75(2):123-128. http://dx.doi. org/10.1177/004051750507500206

34. Ghaly NF. Combined Effect of Polypropylene And Styrenebutadiene Styrene on Asphalt, and Asphalt Mixture Performance. Journal of Applied Sciences Research. 2008; 4(11):1297-1304.

35. Zhou L, Li P, Zhang Z and Chen H. Analysis of Effect of Fiber on High Temperature Performance of Asphalt Mixture. Journal of Wuhan University of Technology. 2008; 30(11):58-61.

36. Zhou L, Li P and Zhang Z. Investigation of High Temperature Properties of Asphalt Mixture Containing Fibers. In: Proceedings of the Material Design, Construction, Maintenance, and Testing of Pavements: Selected Papers From the 2009 GeoHunan International Conference (Geotechnical Special Publication 193); 2009. ASCE; 2009. p. 139-144. 
37. Al-Hadidy AI and Yi-qiu T. Mechanistic approach for polypropylene-modified flexible pavements. Materials and Design. 2009; 30(4):1133-1140. http://dx.doi.org/10.1016/j. matdes.2008.06.021

38. Zhang SL, Zhang ZX, Xin ZX, Pal K and Kim JK. Prediction of mechanical properties of polypropylene/waste ground rubber tire powder treated by bitumen composites via uniform design and artificial neural networks. Materials and Design. 2010A; 31(4):1900-1905. http://dx.doi.org/10.1016/j. matdes.2009.10.057

39. Zhang SL, Zhang ZX, Pal K, Xin ZX, Suh J and Kim JK. Prediction of mechanical properties of waste polypropylene/ waste ground rubber tire powder blends using artificial neural networks. Materials and Design. 2010B; 31(8):3624-3629. http://dx.doi.org/10.1016/j.matdes.2010.02.039

40. Othman AM. Impact of Polypropylene Application Method on Long Term Ageing of Polypropylene Modified HMA. Journal of Materials in Civil Engineering, ASCE. 2010; 22(10):10121018. http://dx.doi.org/10.1061/(ASCE)MT.19435533.0000105

41. Matthews JM and Monismith CL. The Effect of Aggregate Gradation on the Creep Response of Asphalt Mixtures and Pavement Rutting Estimates. In: Meininger RC, editor. Effects of Aggregates and Mineral Fillers on Asphalt Mixture Performance. Philadelphia: ASTM STP 1147; 1992.

42. Mallick RB, Ahlrich R and Brown ER. Potential of Dynamic Creep to Predict Rutting. In: Huber GA and Decker DS, editors. Engineering Properties of Asphalt Mixtures and the Relationship to their Performance. Philadelphia: ASTM STP $1265 ; 1995$.

43. Ramsamooj D and Ramadan J. Prediction of Permanent Deformation of Asphalt Concrete in Cyclic and Monotonic Loading. Journal of Testing and Evaluation. 1999; 27(5):320326. http://dx.doi.org/10.1520/JTE12232J

44. Zhang JN, Cooley LA and Kandhal PS. Comparison of fundamental and simulative test methods for evaluating permanent deformation of hot-mix asphalt. Transportation Research Record. 2002; 1789:91-100.

45. Tashman L, Masad E, Zbib H, Little D and Kaloush K. Microstructural Viscoplastic Continuum Model for Permanent Deformation in Asphalt Pavements. Journal of Engineering Mechanics. 2005; 131(1):48-57. http://dx.doi.org/10.1061/ (ASCE)0733-9399(2005)131:1(48)

46. Chen J-S, Huang C-C and Chang Y-J. Mechanical Responses and Modeling of Rutting in Flexible Pavements. Proceedings of the Eastern Asia Society for Transportation Studies. 2009; 7:1-16.

47. Goh SW and You ZP. A simple stepwise method to determine and evaluate the initiation of tertiary flow for asphalt mixtures under dynamic creep test. Construction and Building Materials. 2009; 23(11):3398-3405. http://dx.doi. org/10.1016/j.conbuildmat.2009.06.020

48. Vardanega PJ, Waters TJ, Spies RE, Ramanujam JM and Nataatmadja A. Ranking Binder Creep Performance Using the ARRB Elastometer. Journal of Materials in Civil Engineering. 2010; 22(5):451-459. http://dx.doi.org/10.1061/ (ASCE)MT.1943-5533.0000043

49. Chen M-Z, Lin J-T, Wu S-P and Liu C-H. Utilization of recycled brick powder as alternative filler in asphalt mixture. Construction and Building Materials. 2011;25(4):1532-1536. http://dx.doi.org/10.1016/j.conbuildmat.2010.08.005

50. Abo-Qudais $\mathrm{S}$. The effects of damage evaluation techniques on the prediction of environmental damage in asphalt mixtures. Building and Environment. 2007; 42(1):288-296. http://dx.doi. org/10.1016/j.buildenv.2005.08.005
51. Abo-Qudais S and Al-Shweily H. Effect of antistripping additives on environmental damage of bituminous mixtures. Building and Environment. 2007a; 42(8):2929-2938. http:// dx.doi.org/10.1016/j.buildenv.2005.05.017

52. Abo-Qudais S and Al-Shweily H. Effect of aggregate properties on asphalt mixtures stripping and creep behavior. Construction and Building Materials. 2007b; 21(9):1886-1898. http://dx.doi. org/10.1016/j.conbuildmat.2005.07.014

53. Roberts FL, Mohammad LN and Wang LB. History of hot mix asphalt mixture design in the United States. Journal of Materials in Civil Engineering. 2002; 14(4):279-293. http:// dx.doi.org/10.1061/(ASCE)0899-1561(2002)14:4(279)

54. Habib A, Hossain M, Kaldate R and Fager GA. Comparison of Superpave and Marshall mixtures for low-volume roads and shoulders. Transportation Research Record. 1998; 1609:44-50. http://dx.doi.org/10.3141/1609-06

55. Khan ZA, Wahab HIA, Asi I and Ramadhan R. Comparative study of asphalt concrete laboratory compaction methods to simulate field compaction. Construction and Building Materials. 1998; 12(6-7):373-384. http://dx.doi.org/10.1016/ S0950-0618(98)00015-4

56. Wang JN, Kennedy TW and McGennis RB. Volumetric and mechanical performance properties of superpave mixtures. Journal of Materials in Civil Engineering. 2000; 12(3):238-244. http://dx.doi.org/10.1061/(ASCE)0899-1561(2000)12:3(238)

57. Parker F, Hossain MS and Song JS. Analysis of quality control and quality assurance data for Superpave mixes. Transportation Research Record. 2000; 1712:25-34.

58. Buchanan MS and Brown ER. Effect of superpave gyratory compactor type on compacted hot-mix asphalt density. Transportation Research Record. 2001; 1761:50-60.

59. Watson DE, Moore KA, Williams K and Cooley LA. Refinement of new-generation open-graded friction course mix design. Transportation Research Record. 2003; 1832:78-85.

60. Xie HB, Watson DE and Brown ER. Evaluation of two compaction levels for designing stone matrix asphalt. Transportation Research Record. 2005; 1929; 149-156.

61. West RC, Moore JR, Jared DM and Wu PY. Evaluating Georgia's compaction requirements for stone matrix asphalt mixtures. Transportation Research Record. 2007; 2001:93-101.

62. Asi IM. Performance evaluation of SUPERPAVE and Marshall asphalt mix designs to suite Jordan climatic and traffic conditions. Construction and Building Materials. 2007; 21(8):1732-1740. http://dx.doi.org/10.1016/j.conbuildmat.2006.05.036

63. Watson DE, Moore J, Heartsill J, Jared D and Wu P. Verification of Superpave Number of Design Gyration Compaction Levels for Georgia. Transportation Research Record. 2008; 2057:75-82. http://dx.doi.org/10.3141/2057-09

64. Lee SJ, Amirkhanian SN and Kwon SZ. The effects of compaction temperature on CRM mixtures made with the SGC and the Marshall compactor. Construction and Building Materials. 2008; 22(6):1122-1128. http://dx.doi.org/10.1016/j. conbuildmat.2007.03.003

65. Jackson NM and Czor LJ. 100-mm-diameter mold used with superpave gyratory compactor. Journal of Materials in Civil Engineering. 2003; 15(1):60-66. http://dx.doi.org/10.1061/ (ASCE)0899-1561(2003)15:1(60)

66. IPC Global. IPC Servopac Gyratory Compactor. Boronia: IPC Global; 2009.

67. General Directorate of Highways. Highway technical specifications. Ankara, Turkey; 2006. Item No. 170/2.

68. Chen $\mathrm{J}$ and Lin K. Mechanism and behavior of bitumen strength reinforcement using fibers. Journal of Materials 
Science. 2005; 40(1):87-95. http://dx.doi.org/10.1007/s10853005-5691-4

69. Keskin M. Determining physical and mechanical differences of asphalt specimens using Superpave and Marshall design methods. [Thesis]. Eskişehir, Turkey: Anadolu University; 2011. [in Turkish].

70. Australian Standards. AS2891.12.1: Methods of Sampling and Testing Asphalt, Method 12.1: Determination of the Permanent Compressive Strain Characteristics of Asphalt - Dynamic Creep Test. Standards Australia;1995.

71. Huang B, Mohammad LN and Wathugala GW. Application of a Temperature Dependent Viscoplastic Hierarchical Single Surface Model for Asphalt Mixtures. Journal of Materials in Civil Engineering. 2004; 16(2):147-154. http://dx.doi. org/10.1061/(ASCE)0899-1561(2004)16:2(147)
72. Witczak M, Bonaquist R, Von Quintus H and Kaloush K. Specimen geometry and aggregate size effects in uniaxial compression and constant height shear tests. Journal of Association of Asphalt Paving Technologists. 2000; 69:733-793.

73. Feeley AJ. UTM-5P, Universal testing machine, hardware reference manual. Boronia: Industrial Process Controls Limited; 1994.

74. Witczak MW, Kaloush K, Pellinen T, El-Basyouny M and Von Quintus H. Simple performance test for Superpave mix design. Washington: National Research Council, Transportation Research Board; 2002. NCHRP Report 465.

75. Hotelling H. The generalization of Student's ratio. Annals of Mathematical Statistics. 1931; 2(3):360-378. http://dx.doi. org/10.1214/aoms/1177732979 
